\title{
Rock On! : Bringing strategic sustainable development to music festivals
}

\section{Sarah Brooks, Dan O'Halloran \& Alexandre Magnin}

\author{
School of Engineering \\ Blekinge Institute of Technology, Karlskrona, Sweden, 2007
}

Thesis submitted for completion of Master of Strategic Leadership Towards Sustainability, Blekinge Institute of Technology, Karlskrona, Sweden.

Abstract: Recreational events gather large numbers of people in concentrated areas for brief periods of time. Effects of these events extend far beyond their spatial and temporal boundaries; a music festival is one such event. This paper asks, "What are some measures that can move music festivals strategically toward sustainability?” A framework for strategic sustainable development based on backcasting from sustainability principles is applied. Research draws on pertinent literature, interviews with festival organizers and an in-depth case study with International Music Concepts. Results indicate that critical flows and management routines upon which music festivals depend contribute to systematic undermining of social and ecological systems. Festival organizers sit at the centre of these flows, and are crucial to changing them. Education to inspire behavioural change of festival organizers and other stakeholders, notably suppliers, audience and artists, appears critical to shifting music festivals toward sustainability. This can be underpinned by building in-house 'sustainability capacity' of festival organisations; creating strategic alliances between festival organizers; and scaling up organisational efforts to include lobbying governments for financial and other support to authenticate a high-level commitment to true sustainable development. Music festivals may then leverage their role in society to move society itself toward sustainability. A template and guidebook are presented to facilitate this shift.

Keywords: Strategic sustainable development, music, festivals, events, backcasting, education. 


\section{Author's note}

This thesis was undertaken in a truly collaborative fashion.

Each member brought particular skills, insights and ideas, the combination of which the project would have been much poorer without.

Dan brought his contacts in the music world, his strong writing abilities, his talent at talking with people and too many good ideas to count.

Alex brought his skills with design, his ability to deeply question, his strong sense of structure and too many good ideas to count.

Sarah brought her strong writing abilities, many critical ideas and her facilitation skills both within the group and with external collaborators.

All major decisions regarding layout, content, methodology, research design, project direction and timing of various aspects of the work were made collaboratively through a consensus decision-making process. All group members reviewed individual contributions and the work was revised based on the group's overall commentary then reviewed again by the entire team. In the end, it is not even clear who did what, as each member contributed so significantly to each piece of our thesis.

It was our privilege to work together. We are grateful for the opportunity, and are highly cognisant of the fact that in the case of Rock On!, the whole is certainly greater than the sum of its parts.

Karlskrona, 2007

Sarah Brooks

Dan O’Halloran

Alexandre Magnin 


\section{Acknowledgements}

We would like to thank everyone who contributed to this work both directly and indirectly, making it such an enlightening and enjoyable experience.

Specifically we would like to acknowledge:

Our primary supervisor, Henrik Ny (BTH): Your guidance during the project kept us on a sound research path while your good nature and humour made working with you a pleasure. Tack så mycket Henrik!

Our secondary supervisor Karl-Henrik Robèrt (The Natural Step / BTH): Your insightful comments as to how we can approach and improve the quality of our research have proved invaluable, while your continuing encouragement as to the importance of all of our projects has inspired us throughout the thesis period.

Our case study subject Tom Lang (Homebake / IMC): Your readiness to give of your time and knowledge, embrace sustainability concepts and engage wholeheartedly in the strategic sustainable development process made the thesis what we think it is: useful, practical and relevant. Thanks Tom.

We interviewed a number of other festival organizers, all with busy schedules, whom we would like to thank for their time and insights into the music festival industry and their enthusiasm for engaging in conversations around sustainability.

Finally, we would like to sincerely thank our shadow group and sustainability colleagues from the MSLS course 2006-07 for their constructive feedback and encouragement, but mainly for their dedication to achieving the vision of a sustainable society. 


\section{Executive summary}

This thesis was undertaken as part of the Strategic Leadership Toward Sustainability Masters program at the Blekinge Institute of Technology, Sweden.

\section{Introduction}

Thousands of music festivals take place each year, with their social and ecological impacts extending well beyond the time and space of the event itself. As a result, there is great potential to implement sustainability initiatives within the festival that influence the broader community beyond the festival bounds.

There is also a growing recognition within the music festival industry that these impacts need to be addressed, and soon (Lang, 2007: pers. comm.). This urgency is evident as organizers struggle keep pace with the preferences of the festival artists and audience for sustainability. However, there is conjecture as to the exact nature of sustainability and how it can be achieved.

The purpose of this paper is to determine some measures that can be applied to music festivals to move them strategically toward sustainability. To do this, it utilizes a framework for strategic sustainable development pioneered by The Natural Step.

\section{Methodology}

The information gathered during the thesis period was predominantly from interviews with industry experts and an in-depth case study with International Music Concepts (IMC), the organizers of the Homebake music festival in Sydney, Australia. This was supported by literature reviews and workshops within the thesis group.

Significantly, a music festival template was completed that provided an understanding of (a) the role of music festivals in society, (b) their social 
and ecological impacts and (c) what a sustainable music festival might look like.

The results are conveyed through a guidebook for music festival organizers.

\section{Results}

The primary outcomes of the research include:

- Evidence that music festivals play a unique role in society, partially satisfying a number of basic human needs by providing a place to gather, dance, play and listen to music while also providing social and artistic enrichment;

- These positive characteristics are countered by the social and ecological impacts of the music festival on natural systems. These impacts are largely characterized by unsustainable flows of energy and materials between the event, society and the biosphere and are presented in a system map; and

- The festival organizer is the 'middle man' between multiple stakeholders and is therefore crucial to move music festivals toward sustainability. The stakeholders that can best assist the festival to achieve its sustainability goals have been identified as the organization itself, the audience, artists and suppliers (including the suppliers of transportation and energy services).

The results of the research were compiled into a guidebook designed to build capacity and confidence of the festival organizer to begin their own transition toward sustainability.

The guidebook begins with an introduction to strategic sustainable development and proposes a draft generic vision of the sustainable music festival. It follows by illustrating where music festivals sit in the broader socio-ecological system. This is done through a system map that illustrates critical material and energy flows and management routines to and from the event.

Six strategic goals, named the 6 strings of sustainability, are then proposed that address the significant physical flows and social goals of the festival. 
Room is also left for individual festivals to create their own «signature goal».

The 6 strings of sustainability for music festivals are expressed within the guidebook as follows:

1. Produce no waste

2. Use $100 \%$ renewable energy

3. Use resource efficient transportation

4. Work with sustainable stakeholders

5. Create an atmosphere of inclusion and respect

6. Drive societal change toward sustainability

....and a festival «signature goal».

A selection of twelve actions is then described in detail to trigger creativity in the festival organizer as they think about how to move toward their strategic goals. The list of actions is not exhaustive, but provides useful examples as the organizer builds their capacity and confidence in the sustainability field.

\section{Key findings}

A number of leverage points to move the festival toward sustainability were identified through the research.

Education and capacity building: The education of the festival organizer is crucial. If the festival organizers are confident with how to strategically plan for sustainability they can enthusiastically share their vision, goals and actions with suppliers and artists, bringing that message to the audience at large.

The Supply chain 'middle man': The festival organizer is the point of contact for numerous and varied stakeholders. For the festival to become sustainable, the organizer depends on the co-operation and creativity of their supply chain. Education and capacity become particularly important in this context as the festival organizer conveys the sustainability message in a way that seems achievable in the short term and beneficial in the long term. 
Form strategic alliances: There is great potential for music festival organizers to join together to shift the attitudes of their key stakeholders, and society at large. Festival organizers joining together could send a clear message to stakeholders that 'this is the direction the industry is going'.

Political support: the festival needs to be profitable. Regulatory or financial signals supporting sustainable development could provide greater confidence that sustainability initiatives and modifications to supply chain practices will be supported and viable.

Realization of potential: Festival organizers appreciate that messages promoted at the festival resonate through the broader community. With music festivals at the cutting edge of social and artistic expression, there is great potential for stakeholders, particularly artists and audience, to receive and act on sustainability ideas and initiatives.

\section{Conclusion}

The success of the framework for strategic sustainable development when applied to music festivals relies on the crucial role of the festival organizer. Leveraging the potential to transform the festival's supply chain and influence society requires capacity in the field of strategic sustainable development.

This requires a shared understanding and definition of sustainability to build a shared vision of the sustainable festival. Strategic goals can then be articulated that will lead the festival from today's reality toward this vision.

We have offered in our guidebook a capacity tool for this. The festival organizer's creativity can then come to the fore as they develop sustainable actions in line with their strategic goals.

The potential of music festivals to leverage their role as leaders of social and cultural trends has only been recently recognized. Whether undertaken on a global scale or by an individual festival, there is significant untapped potential for music festivals to inform and inspire artists, audience and suppliers for the betterment of the festival and society at large. 


\section{Glossary and acronyms}

ABCD method: A strategic tool for backcasting from sustainability principles. "A" denotes the framework, including the system conditions (see below), steps by which to approach compliance with them and the motivation for doing so. " $\mathrm{B}$ " is an assessment of today's current reality from the perspective of the organization. " $\mathrm{C}$ " is the visioning and brainstorming process for a sustainable future. The " $\mathrm{D}$ ” step is the prioritisation of actions developed in " $C$ ", to strategically move the organization toward sustainability, as each action builds upon others.

Backcasting: a planning method by which a successful planning outcome is imagined in the future, and followed by answering the question, "to arrive here, what do we need to do?” or, "what did we do to arrive here?”

Biosphere: that part of Earth and its atmosphere that is capable of supporting life, and in which living organisms exist.

Homebake: The second largest music festival in Australia. Homebake is the case study festival for this thesis.

Human needs: This thesis uses the definition developed by Max-Neef (1992); nine basic human needs are identified: idleness, protection, affection, creation, identity, subsistence, understanding, participation, freedom. They are universal throughout time and culture and may be satisfied in different ways according to context.

IMC: International Music Concepts, the organization responsible for the organization and presentation of Homebake.

IPCC: The Intergovernmental Panel On Climate Changes. Established jointly by the United Nations Environment Program and the World Meteorological Organization.

Photosynthesis: The process by which plants utilize solar energy to convert water and carbon dioxide into carbohydrates and oxygen.

Strategic sustainable development (SSD): Development and planning based on first-order principles for sustainability. This field was pioneered 
by a network of sustainability researchers in cooperation with the Swedish non-governmental organization, The Natural Step.

Sustainability: A state in which society does not systematically undermine natural or social systems within the biosphere.

Sustainability principles: First-order principles for sustainability that are designed for backcasting from sustainability. These principles state that, in the sustainable society, natural systems are not subject to systematic increases of:

- Materials drawn from the earth's crust;

- Substances produced by society;

- Degradation of natural systems by physical means;

And in the sustainable society, people are not subject conditions that systematically undermine their ability to meet their own needs (Robèrt et. al, 2006: xxiii)

SWOT: An evaluative tool used to determine the strengths (S), weaknesses $(\mathrm{W})$, opportunities $(\mathrm{O})$ and threats $(\mathrm{T})$ for an organization.

System conditions: Four conditions based on first-order principles for sustainability (see ‘sustainability principles' above). The system conditions for this work are based on those pioneered by The Natural Step.

Technosphere: Refers to the human system as a sub-system within the biosphere, in which materials, industries and their products interrelate / interact (Robèrt et. al, 2006: 343). 


\section{Table of contents}

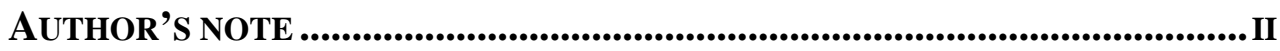

ACKNOWLEDGEMENTS............................................................................II

EXECUTIVE SUMMARY ...........................................................................

GLOSSARY AND ACRONYMS .......................................................................... VIII

TABLE OF CONTENTS.......................................................................... $\mathrm{X}$

LIST OF FIGURES AND TABLES.............................................................XII

1 INTRODUCTION ............................................................................ 1

1.1 Context................................................................................. 1

1.2 Strategic sustainable development................................................. 4

1.2.1 The funnel metaphor ............................................................... 4

1.2.2 Understanding the system: cycles of nature and the laws of

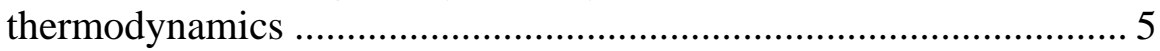

1.2.3 Success: the four system conditions......................................... 6

1.2.4 Strategic planning toward sustainability ................................ 7

1.3 International Music Concepts and Homebake ............................... 9

1.3.1 The Homebake music festival............................................... 9

1.3.2 International Music Concepts .............................................. 9

1.4 Research questions / Scope of project.............................................. 10

2 MethodologY............................................................................... 12

2.1 Research design ..................................................................... 12

2.2 Information collection .............................................................. 14

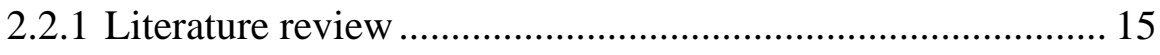

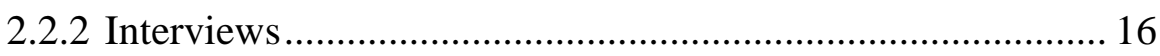

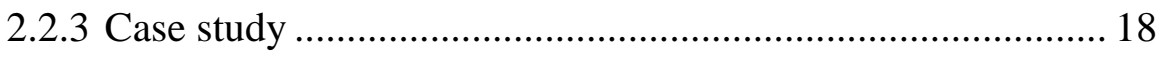

2.3 Information analysis...................................................................... 22

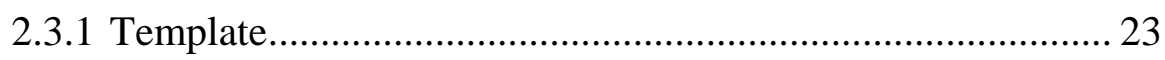


2.3.2 Guidebook 24

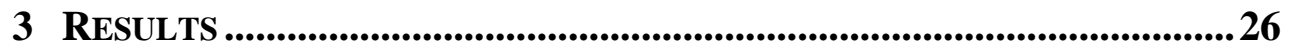

3.1 General results on understanding music festivals......................... 26

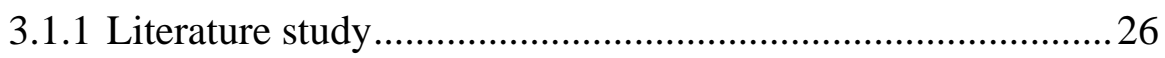

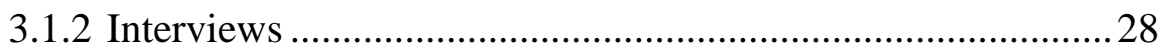

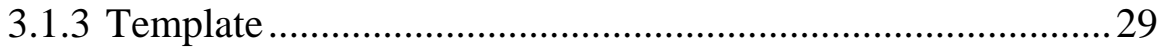

3.2 Homebake: a case study ..............................................................35

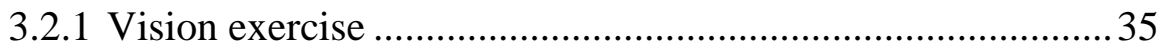

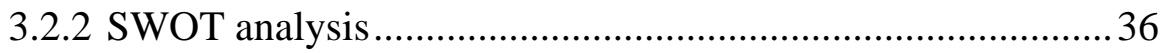

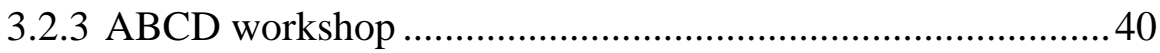

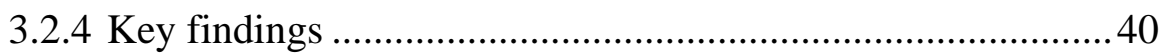

3.3 A guidebook for music festival organizers ......................................46

3.3.1 A capacity tool: generic and practical ................................... 47

3.3.2 A guidebook for a complex system ..................................... 47

3.3.3 Strategic goals: the 6 strings of sustainability ....................... 47

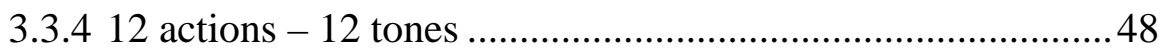

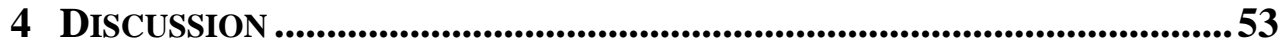

4.1 Primary research question .......................................................53

4.2 Secondary research questions...................................................56

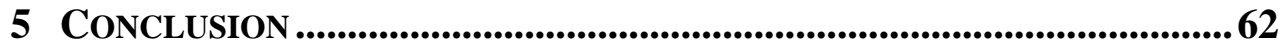

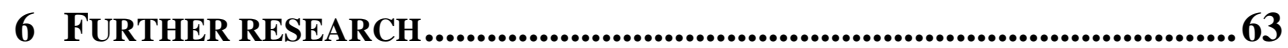

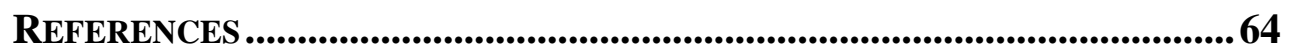

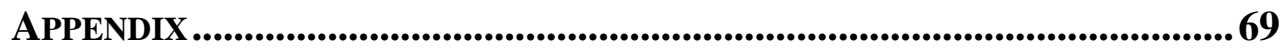




\section{List of figures and tables}

\section{List of figures}

Figure 1.1. Music festivals as part of a larger system .............................. 3

Figure 1.2. The funnel metaphor ......................................................... 5

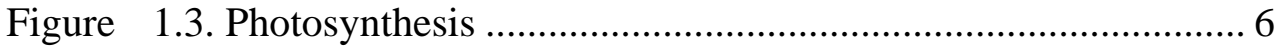

Figure 1.4. Backcasting from a vision of success ................................. 8

Figure 1.5.Map of centre of Sydney........................................................ 9

Figure 2.1. The Maxwell qualitative research design model ................... 14

Figure 2.2. Model for structuring an operational analysis ...................... 20

Figure 2.3. Spiral learning diagram...................................................... 24

Figure 3.1. Homebake's stakeholders in the exterior world .................... 36

Figure 3.2. Model for the operational analysis of Homebake.................. 38

Figure 3.3. System map for music festivals, stakeholders and their

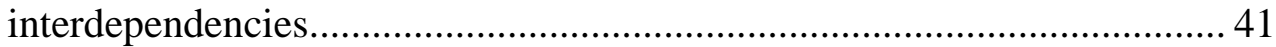

Figure 3.4. The 6 strings of sustainability for music festivals ................ 48

Figure 3.5. Two facing pages for each action in the guidebook .............. 50

Figure 3.6. Scales to help the decision-making in the guidebook............ 51

\section{List of tables}

Table 2.1. Questions and methods matrix results.................................... 12

Table 2.2. Questions and methods matrix ........................................... 13

Table 2.3. Festival organizers interviewed............................................ 17

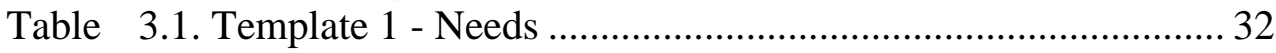

Table 3.2. Template 2 - Concepts ....................................................... 33

Table 3.3. Template 3 - Extended Enterprise .......................................... 34

Table 3.4. Summarized results of the exterior world analysis ................ 37

Table 3.5. Summarized results of the operational analysis ...................... 39

Table 3.6. B Step - Current situation ..................................................... 42

Table 3.7. C Step - Compelling measures (visioning, brainstorming) .... 44

Table 3.8. The 12 tones - Strategic goals and their related actions ......... 49

Table 3.9. Action ranking system........................................................ 51 
..as more and more people wake up to the fact that further growth does not necessarily bring improvements in quality of life (and often exactly the opposite), sustainability is going to become one of the key characteristics with which places want to be associated -- Jonathon Porritt

When the music changes, so does the dance.

-- African Proverb

\section{Introduction}

\subsection{Context}

The publication of the Brundtland Report "Our Common Future" (WCED, 1987) sent the challenge of sustainable development vibrating through all levels of global society. In the decades that followed, much effort has been made to operationalize goals that "meets [sic] the needs of the present without compromising the ability of future generations to meet their own needs" (ibid, 1987:24). To this end, certain successes can be claimed, including, for example, socially, an overall global decrease in the numbers of people living on less than one US dollar a day and, environmentally, an overall increase in the global area (terrestrial and sea) protected to maintain biological diversity (United Nations Statistics Division, 2007). However, the fact remains that current environmental trends indicate a decrease in overall ecosystemic and planetary health (see, for example, Broman et. al, 2002: 717), and an increase in the complexity of those same problems (Holmberg and Robèrt, 2000).

The world is at a critical juncture. News from around the world headlines on an almost daily basis environmental degradation, social injustices and more recently, the looming disasters that are expected to result from climate change (see, for example, Stern 2006; IPCC, 2007: 7; Mittelstaedt, 2007). As we write, the recent release of the Fourth Assessment Report of the Intergovernmental Panel on Climate Change, in which anthropogenic disturbance to natural systems is cited as causing unequivocal "warming of 
the planet" (ibid: 5) is causing massive reactions around the world. Environmental health is no longer an issue reserved for 'professional greenies'. It is an issue that affects all peoples in all areas of the planet.

A lesser-known aspect of the search for sustainability is the conjoining of social sustainability to environmental well-being. Evidence of this partnership is apparent in such activities that produce products that are fairtrade and organic, and in the commitment of the World Bank, one of the world's largest development-focused lending institutions, to go carbon neutral (World Bank, 2007). It is increasingly recognized that to truly meet present and future resource requirements, sustainability must address both social and environmental aspects of society (Robèrt et. al., 2006).

Much of the operalization taking place to ensure long-term sustainability of global systems is aimed at high-impact industries such as the fossil fuel, fisheries and forestry industries (see, for example, Burr, 2006; British Petroleum, 2007; Greenpeace, 2007; Western Canadian Wilderness Committee, 2007; World Wildlife Fund, 2007). However, to ensure longterm sustainability - that is to say: to actually meet the "needs of the present without compromising the ability of future generations to meet their own needs" (WCED, 1987: 24) — it is crucial that all aspects of societal unsustainability be addressed, not just those on the forefront of current concerns or newspaper headlines (for references see, for example, Robèrt et al, 2006). This includes what may be described as recreational or fun activities.

Every year, thousands of events worldwide gather large numbers of people in concentrated areas for a brief period of time. The effects of such events are coming under increasing scrutiny from citizens and organizations concerned with sustainable development (Berlemann and Rhodes, 2005; Olympic Board, 2006; Rossmorris, 2007). Commonly these events are short-lived, often fun, and attended by an audience that is necessarily transient. For these reasons, the impacts of these gatherings are often perceived to be confined to the actual happening. They are not. Planning for these occasions is a year-round, full-time activity involving multiple stakeholders (DuCrou, 2007: pers. comm; Lang, 2007: pers. comm.). The impacts of brief, well-attended events therefore extend well beyond their physical and temporal boundaries. One such event is music festivals. 
Annually, thousands of music festivals occur around the globe (Virtual Festivals, 2006; Lang, 2007: pers. comm.). Like many industries, growing numbers of festivals are adopting 'green' policies. For the music festival industry this includes such actions as composting of food waste, recycling of waste products and attempts to move towards carbon neutrality (Leverentz, 1999; Hall, 2002; Kaufmann, 2006; Virtual Festivals, 2006; Lang, 2007; van Shagan, 2007). Other festivals have not yet implemented any such actions, but there is growing recognition across the music festival industry that sustainability in general must be addressed, and soon (Lang, 2007: pers. comm.).

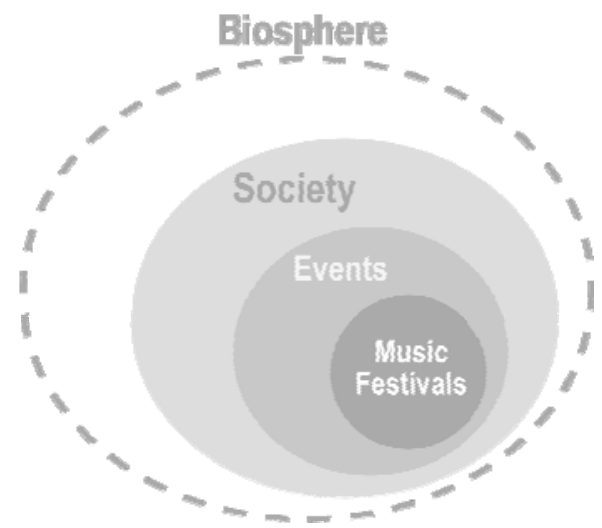

Figure 1.1. Music festivals as part of a larger system

Many music festivals recognize the environmental imperative. However, as in most of society, there is debate as to the exact nature of sustainability what it is at the principle level, and how it can be attained. Much of the conversation centres around the details of how to achieve the elusive thing 'sustainability' - via carbon neutrality, or perhaps renewable energy, or recycling or perhaps something else (DuCrou, 2007: pers. comm.; Lang, 2007: pers. comm.; Rogers, 2007)! We believe that the first step for any organization or industry in reaching sustainability is to define what sustainability means. If we do not know where we are going, it makes it difficult to chart a course for the future. It is our contention that a systemsbased, principle-level understanding of sustainability will shed light on the critical sustainability challenges facing the music festival industry at a principle level, and also highlight strategies to shift it toward overcoming these same challenges. 
The work of The Natural Step ${ }^{1}$ (TNS), a non-governmental organization has been instrumental in developing a systems-based framework for strategic sustainable development. This framework is based on first-order principles for sustainability by which practices can be evaluated and strategies determined upstream (Holmberg et al, 1996; Robèrt et al, 2006: xvii). The following section outlines the concepts of strategic sustainable development and the framework for same. It is this framework that has been used as the basis of a common language between those concerned with issues of sustainability (thus eliminating conjecture over same), and also as a method to plan toward sustainability. We apply this framework here to music festivals in general and one in particular.

\subsection{Strategic sustainable development}

\subsubsection{The funnel metaphor}

The reality of today's unsustainable society is two-fold. Fist, industry has been designed so that concentrations of pollutants emitted to the biosphere continue to increase. Secondly, the biosphere's natural systems are being systematically depleted through physical activities such as over-harvesting (Velisarios, 2001, Harvey, 2004; Sen, 2004; Stern, 2007:iii). The result is that overall the resource potential of the biosphere, and therefore society within it, continues to decrease, while demand for resources continues to increase due to population growth and rising living standards (Dias et al, 2006; Ehrlich, 2006).

These concurrent trends can be illustrated as a 'funnel', giving us a metaphor for the systematic decline in the options available to the unsustainable society over time (Robèrt et. al., 2006).

\footnotetext{
${ }^{1}$ The Natural Step is a not-for-profit organization dedicated to accelerating the transition to global sustainability by guiding governments, organizations, companies and communities onto an "ecologically, socially and economically sustainable path.” (TNS website, 2007)
} 


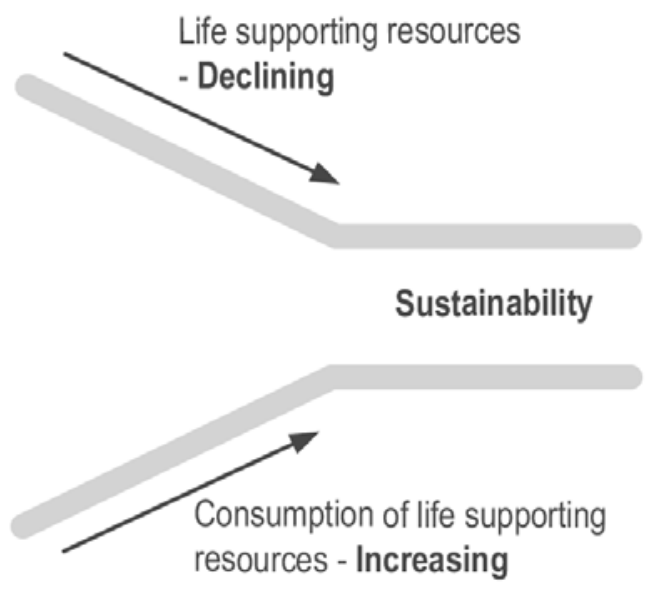

Figure 1.2. The funnel metaphor

The goal of strategic sustainable development is to achieve sustainability by arresting these concurrent trends. To achieve sustainability, we must first be able to define it. To provide an effective definition requires an understanding of how the life supporting systems of the biosphere operate, and an appreciation of how society currently interacts with these natural systems in an unsustainable way.

\subsubsection{Understanding the system: cycles of nature and the laws of thermodynamics}

Scientific principles are the basis of our understanding of the biosphere and how it operates.

Through our understanding of the cycles of nature and the laws of thermodynamics and the conservation of matter, scientists have come to agree that:

- Neither matter nor energy disappears;

- Natural processes disperse matter and energy;

- The value of materials exists in their concentration, structure and purity (e.g. the value of water is in its purity, not its volume);

- Photosynthesis is the primary producer in the biosphere; and

- Humans are a social species. 


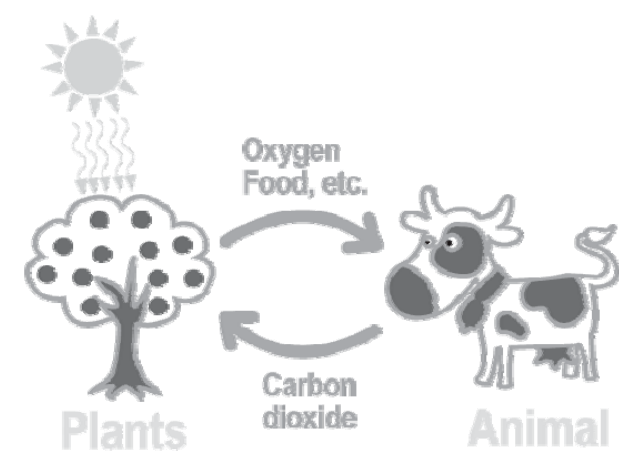

Figure 1.3. Photosynthesis

As a society we continue to allow the physical destruction of the ecosystem while allowing matter and energy to disperse into the biosphere (i.e. pollution), undermining the productive capacity of our natural systems. As a social species we are observing the gap between the haves and the have nots widen, with many unable to meet their basic human needs.

The goal, therefore, is for society to exist within the biosphere such that it does not cause imbalance in nature's cycles, nor stop people's needs from being met. In this way, it is important to recognize that sustainability encompasses both social and ecological dimensions, as we can not achieve one without the other.

\subsubsection{Success: the four system conditions}

Viewing sustainability from the perspective of scientific fundaments, such as the laws of thermodynamics and cycles of nature, directs us to four system conditions for our society to be sustainable.

The first three conditions address ecological sustainability and the mechanisms by which society can destroy the biosphere's life-supporting functions. The fourth condition addresses social sustainability through the repairing of social fabric by enabling individuals to meet their needs.

Whilst much research has been undertaken in defining human needs, we adopt the categories of need defined by Chilean economist, Manfred MaxNeef. Max-Neef defines nine human needs that all must be satisfied if humans are to remain physically, mentally and socially healthy (Robèrt et 
al, 2004). They are subsistence, idleness, understanding, protection, creativity, identity, participation, affection and freedom (Max-Neef, 1992).

With this in mind, the four system conditions for sustainability state that:

In the sustainable society, nature is not subject to systematically increasing...

I. ...concentrations of substances extracted from the Earth's crust,

II. ...concentrations of substances produced by society,

III. ...degradation by physical means,

and in that society...

IV. ...people are not subject to conditions that systematically undermine their ability to meet their needs.

(Holmberg and Robèrt, 2000; Ny et al., 2006)

The sustainability principles take a systems view, considering society within the biosphere, and represent the constraints within which the sustainable society operates. The principles also provide the basis for strategic planning toward sustainability for any endeavour at any scale.

\subsubsection{Strategic planning toward sustainability}

The chief manner by which strategic planning is undertaken within the strategic sustainable development framework is through backcasting (Holmberg and Robèrt, 2000; Robèrt et. al., 2006). Backcasting is a planning procedure that begins by imagining a successful outcome. When backcasting is done from the perspective of sustainability, the successful outcome complies with the principles for sustainability.

Once this vision of success is imagined we follow by asking the question, "what do we do to get there?" or "what do we need to do today to arrive at the successful outcome?” (Robèrt et al., 2006: xvii). This question is answered through the development of motivating and challenging strategic goals that guide the way toward the vision. 


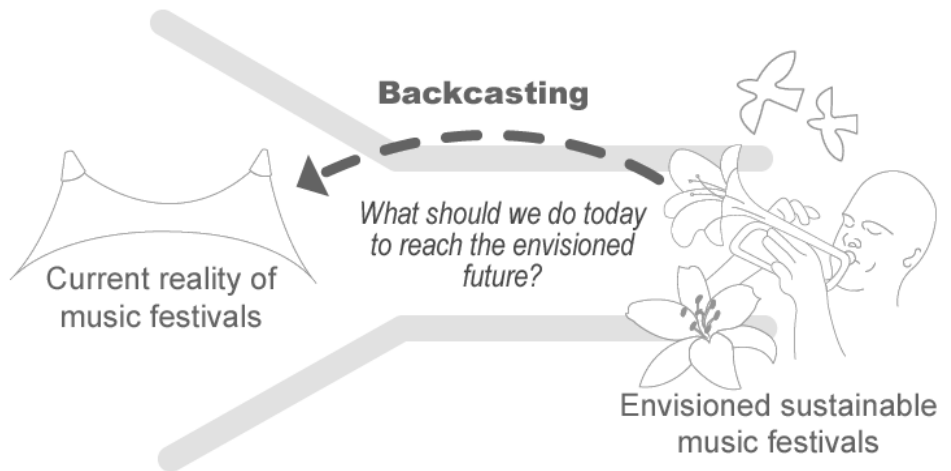

Figure 1.4. Backcasting from a vision of success

Once strategic goals are adopted, specific actions can be adopted that are designed to achieve those goals, moving us strategically toward the vision. When formulating and prioritizing actions it is important to ensure that they:

- Lead toward sustainability (that is, comply with the sustainability principles);

- Provide a base from which future actions can be launched; and

- Provide an environmental, social, financial or other return on investment.

A variety of tools can be employed that can foster actions that are in line with strategic goals on the way to success in the system. These tools can be categorized as:

- Strategic tools that ensure that actions agree with strategic goals to improve the likelihood of success;

- Systems tools that make direct measurements of the system to learn more about the system and assess progress; and

- Capacity tools that help people learn more about sustainability and sustainable development (Robèrt et al., 2006).

The work of this thesis utilizes the framework for strategic sustainable development and its endemic planning tools. It focuses on identifying ways in which music festivals can move toward compliance with the sustainability principles. One music festival in particular, Homebake, and 
its parent organization International Music Concepts, was especially eager to understand their festival from this perspective of strategic sustainability.

\subsection{International Music Concepts and Homebake}

\subsubsection{The Homebake music festival}

Homebake takes place annually in the first week of December in Sydney, Australia. It occurs in the Royal Botanic Gardens, in the heart of Sydney (Figure 1.5) and is attended by approximately 20,000 people. The Homebake music festival showcases cutting-edge Australian and New Zealand bands and is organized and implemented by International Music Concepts.

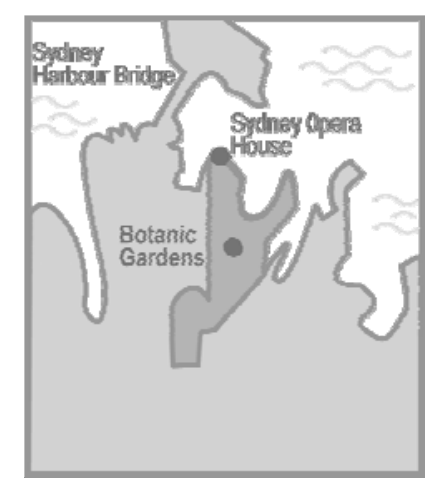

Figure 1.5.Map of centre of Sydney

\subsubsection{International Music Concepts}

Founded in the late 1980s, International Music Concepts (IMC) is an Australian company based in Sydney. It began its life as a management organization for underground punk styles of the time, working in various capacities as tour promoter, publicist and management for both international and Australian bands (IMC website, 2007; Lang, 2007: pers. comm.). Since that time, IMC has grown to looking after many wellknown Australian bands. International Music Concepts is primarily comprised of two co-directors, Tom Lang and Joe Segreto. 
Recently, the founders of Homebake have begun to heed pressure from artists and the festival industry, who are sounding the call to sustainability. The directors of Homebake's parent organization, International Music Concepts (IMC) believe that it is necessary to address their issues of contributing to unsustainability for the following reasons:

- There is a growing pressure from outside stakeholders (concert attendees, festivals performers) to become more sustainable;

- Regulatory shifts that require increased sustainability by all industries loom on the horizon, particularly in response to growing concerns over climate change;

- There is a sense that something is 'not right' with the world, and IMC feels a responsibility to behave 'correctly'; and

- It makes good business sense - IMC believes that sustainable businesses are businesses that will persist into the future (Lang, 2007: pers. comm.).

"Every year, the festivals I attend are making more and more of an effort [to be more sustainable]...we definitely recognize the need to be more sustainable." --Tom Lang (co-director, IMC)

IMC has recognized the sustainability imperative, and was eager to collaborate to shift its festival toward sustainability.

\subsection{Research questions / Scope of project}

The purpose of this thesis was to discover how to make music festivals more sustainable, and was addressed by the following research questions.

Our primary research question was:

What are some measures that can move music festivals strategically toward sustainability?

The purpose of this was to collaborate with various festival organizers and one in particular (International Music Concepts) to understand and reduce the gap between the current situation and desired future of music festivals when considered from the perspective of sustainability. 
Breaking this question down, we developed three secondary research questions. Each question was designed to add a necessary element to the primary subject:

1. What do music festivals look like now from a perspective of strategic sustainability?

This question guided the identification of critical material and energy flows and management routines as seen from a perspective of strategic sustainable development.

2. What do music festivals look like in a sustainable society?

Answering this question provided a vision of a 'successful' music festival at a principle level, designed in compliance with the principles for sustainability (1.2.3).

3. How can we close the gap between music festivals now and in the sustainable society?

The previous two questions illustrate the tension between where music festivals are now, and where they might be in a sustainable society. This question asks how we may address the tension, reducing the distance between where we are currently and where music festivals would like to be in the sustainable society. 


\section{Methodology}

\subsection{Research design}

A questions and methods matrix was completed to link the primary and secondary research questions to the research methods that were most likely to provide useful information. These results are summarized below in Table 2.1 and Table 2.2.

Table 2.1. Questions and methods matrix results

\begin{tabular}{|c|c|c|c|c|c|c|}
\hline & Question & Lit. review & $\begin{array}{l}\text { Interviews } \\
\text { discussion }\end{array}$ & Template & Guidebook & $\begin{array}{l}\text { Case } \\
\text { study }\end{array}$ \\
\hline 1 & $\begin{array}{l}\text { Potential } \\
\text { measures to } \\
\text { move music } \\
\text { festivals toward } \\
\text { sustainability }\end{array}$ & $X$ & $X$ & $X$ & $X$ & $X$ \\
\hline $2 a$ & $\begin{array}{l}\text { Music festivals } \\
\text { today }\end{array}$ & $X$ & $X$ & $X$ & & $X$ \\
\hline $2 b$ & $\begin{array}{l}\text { A vision for } \\
\text { music festivals }\end{array}$ & & $X$ & $X$ & & $X$ \\
\hline $2 c$ & $\begin{array}{l}\text { How to close the } \\
\text { gap? }\end{array}$ & $x$ & $X$ & & $X$ & \\
\hline
\end{tabular}


Table 2.2. Questions and methods matrix

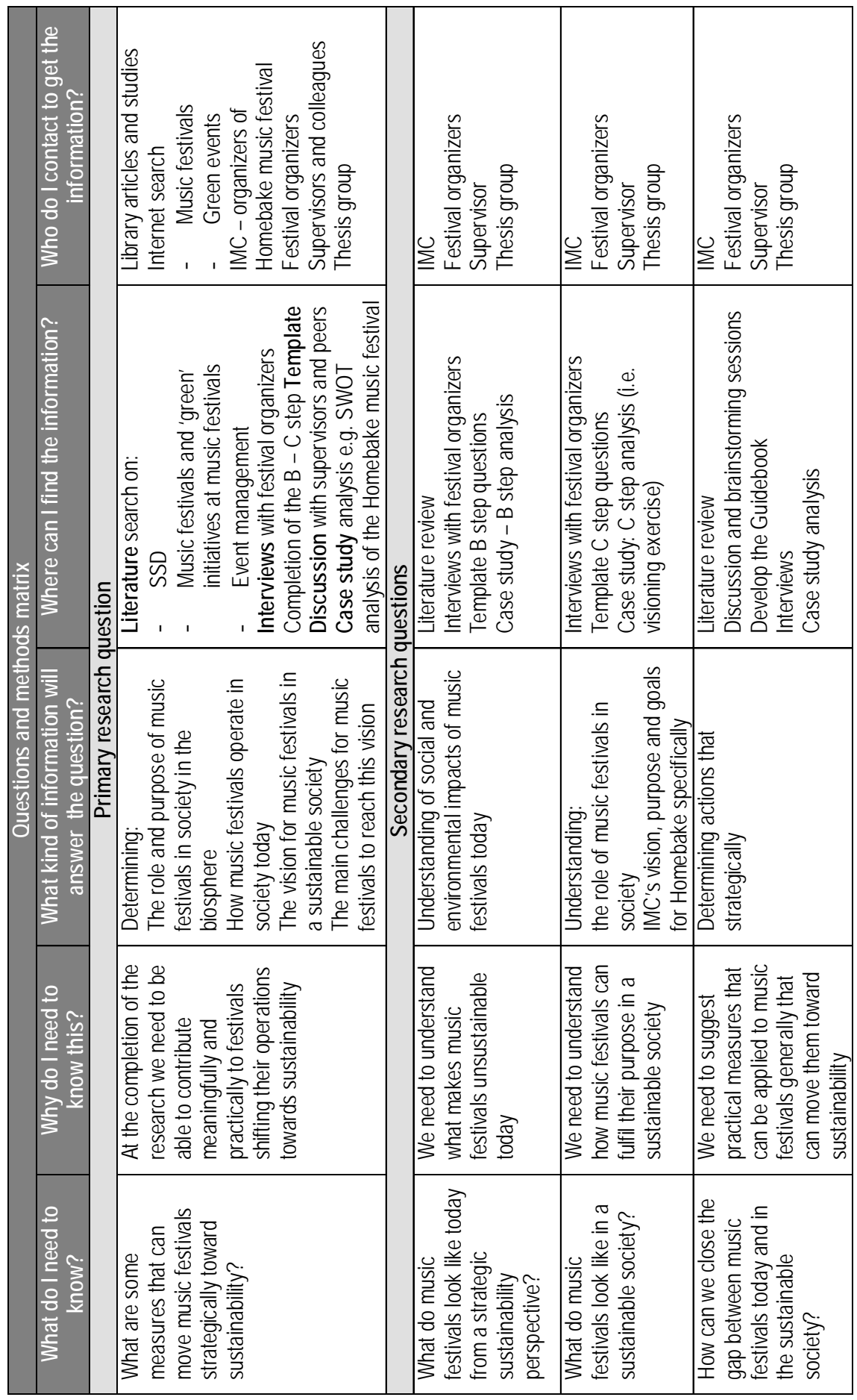


The research design was further facilitated by the use of Maxwell's qualitative research design model (Figure 2.1). The model shows the integrated and interacting nature that the five components of effective qualitative research possess (Maxwell, 2005), reflecting the fact that collecting and analysing data, developing theory, fine tuning research questions and ensuring validity are processes that occur iteratively and simultaneously (ibid, 2005).

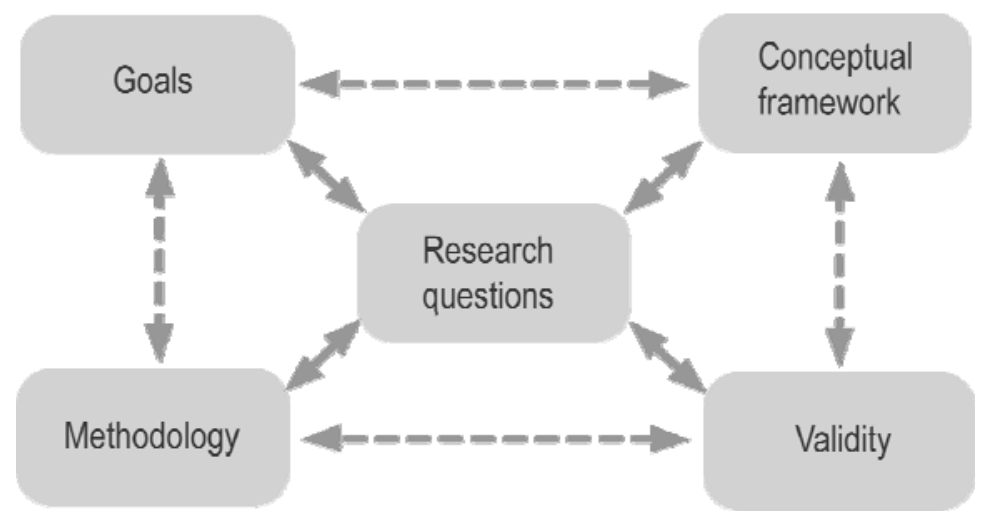

Figure 2.1. The Maxwell qualitative research design model Source: Maxwell 2005

By using Maxwell's model we were able to ensure that iterations to the aims of the research were undertaken systematically, with all research components aligned.

In the sections below the methods for information collection and information analysis are presented. For each section the validity issues that arose are stated. The countermeasures employed to ensure validity are then discussed in the Discussion section 4.

\subsection{Information collection}

Having identified appropriate methods with which to address our research questions, we now explain in greater detail how each method was applied to obtain the desired information. 


\subsubsection{Literature review}

\section{Purpose:}

1. To establish the case for researching strategic sustainable development;

2. To discover if research has been or is being undertaken in the field of strategic sustainable development for music festivals; and

3. To accumulate relevant information that links sustainability and music festivals either directly or indirectly.

\section{Topics researched:}

- Strategic sustainable development;

- Strategic sustainable development and event planning;

- Music festivals (focussing on existing and proposed 'green' and social initiatives);

- Event planning generally; and

- The business case for sustainability.

\section{Sources:}

- Books;

- Academic texts;

- Peer reviewed journal articles;

- Internet i.e. Music festival websites and festival organizers; and

- Governmental and non-governmental organization reports.

\section{Outcome:}

- Sufficient materials to establish the requirement for strategic sustainable development in the global context;

- No academic material discovered that specifically related the application of strategic sustainable development and music festivals; and

- There was a scarcity of peer-reviewed literature regarding green festivals; most of this information was discovered on the internet through websites, news articles and journals.

\section{Validity:}

With a relative scarcity of peer reviewed academic material specifically on music festivals and strategic sustainable development, the literature review did not provide a significant amount of information. It did assist in 
establishing the case for strategic sustainable development that applies to music festivals, as it does to society generally.

\subsubsection{Interviews}

\section{Purpose:}

1. To provide context and understanding of the music festival industry;

2. To assist in the development of a template and guidebook for music festival organizers;

3. To add to the information accumulated during the Homebake case study (see below) regarding critical material, energy and management issues; and

4. To better appreciate festival organizer's understanding of strategic sustainable development.

\section{Questions:}

The interview questions were designed around three key questions, namely

1. What does sustainability mean to you?

2. What are your main sustainability challenges? and

3. What are you doing to address these challenges?

Further, additional questions arose through the process of developing the music festival template. These questions included:

1. What is the role of the music festival in society? and

2. What are some leverage points that music festivals have in moving society toward sustainability?

In the context of our discussions around the preparation of a guidebook, we were also interested in discovering what music festival organizers would find practical and useful in their transition toward sustainability.

Therefore, the questions posed to each interviewee were as follows: 
1. What is, in your opinion, the role of a music festival in society?

2. How does it fulfil that role?

3. What does sustainability mean to you as a festival organizer?

4. According to this definition, what are your top 3 sustainability challenges?

5. What are the top 3 barriers to overcoming these challenges?

6. Which of your organization's talents are, in your opinion, most useful to help drive sustainability?

7. In your opinion, what are the strengths of music festivals in general that can assist society in becoming more sustainable?

8. What is it that would be most helpful to you at this time to help you move toward sustainability?

9. Why would these be most helpful?

\section{Interviewees:}

Six music festival organizers were interviewed with responses transcribed to the interview template. The music festival organizers interviewed are listed in Table 2.3 below:

Table 2.3. Festival organizers interviewed

\begin{tabular}{ll}
\hline Interviewee & Music festival \\
\hline Andrew Tatrai & Live Earth (Australia) \\
\hline Jess Decrue & Splendour in the grass (Australia) \\
\hline Vera Rizzo & Big Day Out (Australia) \\
\hline Unnamed source & Live Earth Green Code (USA) \\
\hline Danny Rogers & Saint Jerome's Laneway Festival (Australia) \\
\hline Tom Lang & Homebake Music Festival (Australia) \\
\hline
\end{tabular}

\section{Validity:}

The number of interviews undertaken does not constitute a representative sample of the music festival industry. There was also limited time in which to establish a shared understanding of sustainability with festival interviewees prior to conducting the interview. 


\subsubsection{Case study}

A case study was undertaken with International Music Concepts (IMC), the organizers of the Homebake music festival in Sydney, Australia. Workshops were predominantly conducted over the phone with templates provided for IMC to populate and return to the thesis group.

The Homebake case study included three main activities:

- A vision exercise;

- A internal and external analysis; and

- An ABCD analysis.

\section{The vision exercise}

To understand Homebake's core purpose and values, a visioning exercise was undertaken where IMC were asked to define Homebake's core purpose, values and goals by answering the following questions:

\begin{tabular}{ll}
\hline Core purpose & $\begin{array}{l}\text { "What is Homebake's fundamental reason for being is } \\
\text { and what does it contributes to society?" }\end{array}$ \\
\hline Core values & $\begin{array}{l}\text { "What characteristics are inherent to Homebake, } \\
\text { giving it its personality or identity?" }\end{array}$ \\
\hline Strategic goals & $\begin{array}{l}\text { "State up to 9 goals that are challenging and inspiring } \\
\text { to IMC that help the festival fulfil its purpose." }\end{array}$ \\
\hline
\end{tabular}

\section{Validity:}

The vision exercise was undertaken at the commencement of the project and as a result there was not a clear understanding of the difference between purpose, values and goals.

The exercise was undertaken with only one of the two key personal at IMC.

\section{Internal and external analysis}

An "exterior world" and "internal operational" analysis of Homebake was undertaken with IMC. This type of analysis is also referred to as a SWOT 
analysis as we seek to discover the Strengths, Weaknesses, Opportunities and Threats that Homebake faces with respect to sustainability.

\section{Purpose:}

To identify the strengths, weaknesses, opportunities and threats of Homebake's internal and external operations (i.e. interaction and relationship with stakeholders) when considered from the perspective of sustainability and the sustainability principles.

\section{Internal analysis:}

For the internal analysis IMC was provided a visual representation of their operations (Figure 2.2 below), to assist them in answering the following questions.

1. What services do the festival deliver?

2. What does the festival depend on?

3. What remains during the planning and at the end of the festival? and

4. What does the operation of Homebake look like, that is: what are the internal functions and the culture of the festival? (Robèrt et al, 2006).

\section{External analysis:}

For the external analysis IMC was provided with a model listing Homebake's stakeholders. This was then modified and verified by IMC. Positive and negative aspects of each relationship were then identified and listed through discussion between the thesis group and IMC.

\section{SWOT analysis:}

Integrating both the internal and external analyses, IMC were asked to consider:

1. Which aspects of the exterior world and internal operations risk having a significant impact, both positive and negative, on Homebake's ability to reach its vision;

2. How do these aspects impact on Homebake's potential to adhere to its core purpose, values and goals, and the sustainability principles; and

3. Which aspects constitute strengths, weaknesses, opportunities or threats (Robèrt et al, 2006).

The aspects identified were then categorized as strengths, weaknesses, opportunities or threats together by the thesis group and IMC. 


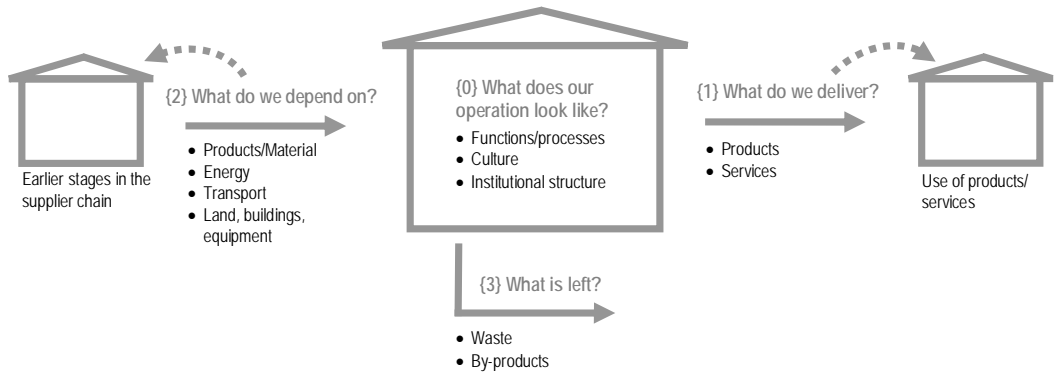

Figure 2.2. Model for structuring an operational analysis

Source: Robèrt et al. (2006)

\section{Validity :}

Due to IMC's time constraints, we provided the initial template populated with our ideas as to Homebake's strengths, weaknesses, opportunities and threats. Ideally this would have been created independently by IMC.

\section{$\underline{\text { Strategic planning exercise }}$}

For the final exercise we conducted a strategic planning exercise known as an ABCD workshop over six separate phone interview sessions. The purpose of the ABCD workshop is to guide the festival strategically towards sustainability through the following four steps.

\section{Step A:}

The A step is designed to create a shared mental model for sustainability.

To do this a PowerPoint presentation was delivered to IMC to provide:

1. An awareness of the global bio-geochemical cycles and Homebake's place within this system;

2. An introduction to the limitations of the biogeochemical cycles, as illustrated by "the funnel" metaphor; and

3. An understanding of the four system conditions for sustainability.

\section{Step B:}

The B step provides an assessment of "today" by identifying flows and practices that are problematic from a sustainability perspective (Robèrt et al, 2004). The results of IMC's SWOT analysis were discussed with flows and practices categorized according to sustainability principle in order to: 
1. Reinforce IMC's understanding of the sustainability principles;

2. Highlight Homebake's sustainability challenges; and

3. Highlights their assets in relation to sustainability.

\section{Step C:}

The C step involves creating solutions and visions for "tomorrow" within the constraints of the sustainability principles. To do this, brainstorming and discussion between the thesis group and with IMC was undertaken:

1. To create a principle-based vision for the sustainable music festival;

2. To better detail specific solutions to Homebake's sustainability challenges;

3. To identify "low-hanging fruit" i.e. the more obvious areas for improvement that could provide early success and momentum for continued improvement; and

4. To identify existing initiatives that are appropriate platforms for further development toward the vision.

\section{Step D:}

The D step involves prioritising the solutions developed during the $\mathrm{C}$ step exercise. The actions suggested should be prioritized based on the following questions:

1. Does the action move the festival towards the sustainable music festival vision;

2. Does the action have potential for further development as the music festival moves toward the vision (i.e. the action is seen as a "flexible platform”); and

3. Does the action provide the organization an appropriate financial, social, environmental or other return (Robèrt et al, 2006).

Whilst a number of actions were identified during the $\mathrm{C}$ step activity for Homebake, the D step was not completed in this case study i.e. the actions were not prioritized. IMC was provided with a copy of The Sustainable Music Festival: A strategic guide (section 2.3.2 below), which explains the prioritization process.

The ABCD workshop was run through a series of phone calls over four weeks. Most of the workshop was undertaken only by one half of the directing team for IMC - Tom Lang. We were concerned that running such a workshop with three of 'us' (the thesis team) and one of 'them' (Tom) would cause him to feel limited in his expression of creativity. Using the 
information we had gathered prior to the workshop, we were able to facilitate the conversation by asking questions of Tom, and inviting him to share his expertise. During the "B" step of the workshop, questions were posed in the following manner: "And does that [aspect of organizing a music festival] use any substances that are drawn from the lithosphere (substances produced by society etc.)?” If the answer was yes, the next question was generally "and do you know if that contributes to systematic increases of that substance in natural systems?" During the "C" step portion of the workshop, ideas were initially posed, "and do you think ... might work?”

Asking these questions made it possible for Tom to identify IMC's own critical flows, materials and management routines thereby giving him ownership of the process. It is difficult to measure the exact outcomes of such a sense of ownership. However, we found Tom increasingly enthusiastic and excited as he moved through the process, particularly when he began to identify opportunities and steps IMC could take to move Homebake toward a vision of success.

\section{Validity:}

The strategic planning case study focussed on one specific festival with lessons that may not be perfectly transferable across the industry;

Due to information and time restrictions, the D Step analysis was not completed; and

The ABCD workshop was undertaken with only one half of the directing team for IMC - Tom Lang.

\subsection{Information analysis}

The methods above were used to gather relevant information. This information was then analysed and presented within a music festival template and a guidebook. 


\subsubsection{Template}

\section{Purpose:}

1. To facilitate bridging the knowledge gap between sustainability experts and festival organizers;

2. To provide an overview of the sustainability challenges facing the music festival industry and bring the most relevant challenges to the attention of the music festival organizer; and

3. To trigger creativity in the development of solutions to these sustainability challenges.

\section{Template format:}

The template (as adapted from Ny, 2006) consists of three smaller templates or columns that ask questions under the following headings:

1. Needs -what human needs ${ }^{2}$ (Max-Neef, 1992), desires and functions does the music festival satisfy and serve in society?

2. Concepts -how could those needs, desires and functions be satisfied or served by the music festival in principle?

3. Extended enterprise -what is the potential for the music festival to influence societal changes through communication? (Ny, 2006)

The discussion within each of the templates is guided by questions related to the $\mathrm{B}$ (current situation) and $\mathrm{C}$ step (vision or solutions) of the backcasting process (Ny, 2006). The template does not consider D step solutions and prioritisation of actions.

\section{Completing the template:}

- The template questions were answered by the thesis group with these answers reviewed by supervisors experienced in the development and use of the template;

- The answers built on the understanding gained from the literature review, interviews and case study; and

- It was also offered to music festival organizers for review and modified according to their input.

\footnotetext{
${ }^{2}$ Max-Neef defines nine human needs to be satisfied if individuals are to remain physically, mentally and socially healthy (Robèrt et al, 2004). They are subsistence, idleness, understanding, protection, creativity, identity, participation, affection and freedom (MaxNeef, 1992).
} 
The methods by which information collection and analysis were employed are illustrated in the diagram below: the literature review informed the development of the template, which was developed in partial collaboration with IMC. Interviews were conducted to validate our findings. At this point, the literature was revisited, as was the template and the case study. This 'spiral learning' led us then to the development of the guidebook.

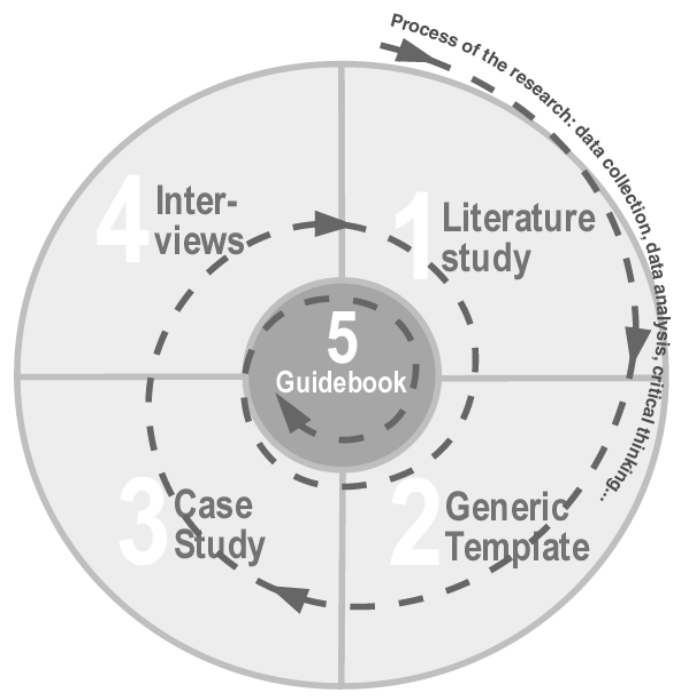

Figure 2.3. Spiral learning diagram

\section{Validity:}

Whilst reviewed by academic staff experienced in the use of the template, the template itself has not yet been reviewed by the music festival organizers. The original template was designed for sustainable product development purposes. Some of the questions required minor adjustments to language to better accommodate the music festival discussion.

\subsubsection{Guidebook}

\section{Purpose:}

1. To be a stand-alone, user-friendly document for festival organizers to refer to as they transition their events towards sustainability;

2. To provide meaningful and practical information on some actions festival organizers can take to transition their festivals toward sustainability; and 
3. To clearly relate the music festival to broader ecological and social systems.

\section{Guidebook format:}

1. Introduction to strategic sustainable development;

2. A draft generic vision statement for sustainable music festivals;

3. Identification of the 6 strategic goals for music festivals as they move toward sustainability, with space for a festival's «signature goal»; and

4. 12 suggested actions for festival organizers including: the stakeholder(s) and strategic goal that the action relates to; the influence of the action in the system; supporting actions; and expected results from taking these actions.

\section{Completing the guidebook:}

The guidebook was populated through:

- Group discussion and brainstorming of ideas;

- Literature search;

- Homebake case study; and

- Interviews with industry experts.

\section{Validity:}

The guidebook utilizes the information gathered during the literature study, interviews, template and case study. It is currently under review by a panel of festival organizers and other people concerned with events and sustainability. 


\section{$3 \quad$ Results}

This section presents results compiled from literature and interviews. It also presents the larger results stemming from our research and is based on the following structure:

- Findings on understanding music festivals in general are presented. These results are corroborated through our literature study and interviews and are summarized in the development of a template identifying (a) the role of music festivals in society today, (b) their social and ecological impacts, and (c) what a sustainable music festival might look like. This section addresses the first and second secondary research questions;

- A case study of Homebake, wherein the general results and conclusions are tested against a real festival and its parent organization is presented. This section sheds light on the primary research question, and addresses the three secondary research questions; and

- Finally, we describe in detail the outcome of the general work and its test against Homebake: a guidebook designed to help music festival organizers concerned with shifting their festivals toward sustainability. It is our answer to the primary research question, "What are some measures that can move music festivals strategically toward sustainability?”

Section 4 discusses the implications of this work, highlighting the relevancy of our efforts, areas of strength and also those to be improved.

\subsection{General results on understanding music festivals}

\subsubsection{Literature study}

Literature pertaining to sustainability and music festivals is relatively scarce. An in-depth search reveals that while there is a definite trend toward recognizing the need to address sustainability, the manners in which this may most effectively occur remain elusive (see, for example Hall, 2002; Kaufmann, 2006; Lang, 2007). Most commonly, it is solely the 
environmental imperative that is identified as the driver of attempts-towardsustainability in music festivals. Thus we find references to such actions as composting at such events, increasing inclination by festival organizers to recycle, and attempts at becoming carbon neutral (Leverentz, 1999; Virtual Festivals, 2006; Lang, 2007; Live Earth, 2007; van Shagan, 2007;). References to the social effects of music festivals in society generally tend to be limited to references to crowd behaviour or violence, and the economic results of hosting music festivals (Timo 2005; Vider, 2004). That said, there is an ample body of literature indicating the need for sustainability.

The recently released Stern and IPCC Reports (IPCC, 2006; Stern, 2007) indicate a clear and growing recognition across society that the natural environment is changing and that this change has far-reaching consequences. Indeed, the planet is changing at a rapid rate; this affects all peoples around the globe (Dias et al., 2004; Steffen et. al, 2004; United Nations, 2007). Thus it will also affect socio-ecological sustainability (Steffen et al., 2004). This includes those who organize music festivals as well as the festivals themselves (Rossmorris, 2007). Clearly the requirement for more sustainable development is recognized.

Further studies reveal strong need for a strategy to address sustainable development (see, for example, Holmberg and Robèrt, 2000; Ny et al. 2006). Arguably, a considered, systematic application of a strategy for sustainable development such as the framework presented in this paper may contribute in the success of an undertaking, providing concerted direction and tools to support the endeavour to which the strategy is applied (Robèrt, Daly and Hawken, 1997; Nattrass, 1999; Robèrt et. al., 2002,). Case studies of applying this strategic framework bear this out (Natrass, 1999; Robèrt, 2002; James and Lahti, 2004; Whistler Resort Municipality, 2007). The gap in the literature regarding application of this framework for strategic sustainable development to music festivals encouraged us to move forward with the project.

Conversations with academics versed in strategic sustainable development; those involved with music festivals; festival organizers; and our in-depth literature search over a period of three months indicate that this gap in the research and literature pertaining to strategic sustainable development and music festivals is truly present, and our search for research in this area 
thorough. The results of our literature review were scrutinized against findings from interviews with industry experts.

\subsubsection{Interviews}

Interviews were undertaken with six festival organizers, each responsible for the organization and presentation of separate festivals. A series of nine questions were developed, designed to illuminate sustainability-related issues currently facing music festival organizers. The questionnaire inquired as to what festival organizers believe the role of music festivals to be in society, and the manners in which festivals fulfil that role. Individual organization's understanding of sustainability was explored, as were the main challenges and opportunities as regards sustainability and that face music festivals today.

General suppositions that can be drawn from the results of the literature and interviews include:

1. There is a growing recognition among music festival organizers that sustainability is an issue that must be addressed soon;

"It [sustainability] couldn't be more relevant than right now" -Tom Lang (co-director, IMC)

2. Many festival organizers believe that those who take a leadership role in addressing sustainability will benefit from a competitive advantage and also gain a good reputation in the industry. This is corroborated by the literature (Willard, 2005; DuCrou, 2007: pers.comm.; Rogers, 2007: pers. comm.);

3. Music festival organizers generally have a will to address sustainability, but are unclear as to 'best practices' and immediate steps to take that will improve their chances of arriving at sustainability;

4. As in most of society, there is conjecture among festival organizers as to the exact nature of sustainability - what it is, and what it looks like as a goal. This confusion limits industry-wide collaboration, as every organization works or fails to work towards its own version of sustainability. For example, one of the festival organizers interviewed identified noise restrictions as one of the top three sustainability challenges that they faced (Rogers, 2007: pers. 
comm.), while another identifies not owning the land on which their festival occurs as one of their major barriers to sustainability (DuCrou, 2007: pers. comm.). Some festivals see social infringement on local communities through noise as a major issue, while others focus more on the ecological impacts of music festivals; and

5. Finally, it became very clear through our conversations that most festival organizers struggle with the amount of information regarding sustainability today. Many organizers are unable to differentiate between actions towards sustainability, such as recycling, tools to facilitate the shift toward sustainability, such as books, and the state of sustainability itself. The details are overwhelming.

"[we need] an educator...who understands these issues and who can bring parties together for a common goal"-Danny Rogers (manager, St. Jerome's Laneway Festival)

There is therefore a need to address sustainability within the music festival industry strategically and at a principle level. The details can then be left to develop appropriate to the context from which they emerge.

\subsubsection{Template}

The results of our general understanding of music festivals are summarized in the following templates. The templates are a compilation of information gathered from literature and interviews. They are also the outcome of many brainstorming sessions our team carried out in an effort to broaden our thinking around music festivals and sustainability.

This work resulted in the templates below, based on the structure and master template matrix developed by Henrik $\mathrm{Ny}$ and colleagues ( $\mathrm{Ny}, 2006)$ of the Blekinge Institute of Technology. The templates are separated into three distinct entities. The first template addresses the needs ${ }^{3}$ (Table 3.1) which music festivals fulfil and the role that music festivals play in society, or: why music festivals exist today, and what niche they fill. In this template, 'market' refers to all members of the general public that are financially linked to the festival (e.g. audience, suppliers, artists,

\footnotetext{
${ }^{3}$ Needs are based on the Max-Neef (1991) categories of human need.
} 
competitors, sponsors, etc.). Primary findings of the needs template are as follows:

- Music festivals partially satisfy ${ }^{4}$ a number of the basic human needs, most notably participation, identity, idleness and creativity, and exist largely to fill these needs;

- Many of the market desires associated with these needs are in a state of rapid flux as society becomes more aware of its role(s) in unsustainability. There will likely be an increasing demand for sustainable services and infrastructure overall, and this will affect festival organizers in how festivals are designed, the types of music (creative content) that may be preferred, and the types of services festival goers will expect at the event itself; and

- Some festivals are already considering these evolving market trends and gaining competitive advantage by jump-starting their sustainability plans.

The second template addresses the conceptual design (Table 3.2) that music festivals currently utilize, and how that design could change in the future. That is to say: how music festivals fill the niche that they do from a perspective of the sustainability principles. Primary findings of the concept template include:

- Most, if not all, of the critical flows of material and energy are net contributors to unsustainability; they contribute in multiple ways to the systematic increase of toxic, scarce or persistent materials in natural systems, or contribute to the systematic degradation of those same systems. These patterns are reflected in the management routines associated with music festivals, as these are largely dependent on the critical flows of energy and materials;

- Music festivals have potential to help society more easily comply with the sustainability principles by leveraging their role as a middle man. This can effect change throughout a supply chain, resulting in an overall shift toward more sustainable services and products that will be available to everyone; and

- Music festivals can also help society more easily comply with the sustainability principles by leveraging their opportunities to

\footnotetext{
${ }^{4}$ Satisfiers are the means by which needs are fulfilled (Max-Neef, 1991); one need may have many satisfiers. Needs are constant across the whole human family, but satisfiers vary across cultures.
} 
decouple services from unsustainable flows of materials; substituting harmful or toxic materials for benign ones; making more efficient use of materials; and recycling others. This allows festivals goers of sustainable music events, who number in the millions every year, to 'do the right thing' without having to think about it.

The final template explores the extended enterprise (Table 3.3) of music festivals: the manners in which music festivals currently act or fail to act as drivers of societal change toward sustainability. This template also addresses ways in which music festivals may do more to become even greater drivers of a societal shift toward sustainability in the future. Primary findings from this template include:

- Many music festivals promote unsustainable behaviour, both implicitly and explicitly due to the fact that they are often seen as a day or days of escape, and an excuse to engage in excessive behaviour (e.g. drugs, alcohol and disrespect). Promotion of such can also occur through showcasing bands whose own behaviour reflects and encourages such excess. It may also occur by utilizing advertising that itself uses and encourages fashions that are unsustainable with respect to body image, fame and so forth;

- Societal barriers such as the perception that sustainability is the provenance of 'dirty hippies' are a major stumbling block to music festivals becoming more sustainable. There is also a pervasive sense that to be sustainable means having a lack of (wealth, fun, luxury, comfort). Thus there is a need for sustainability to become (even) cool(er!); and

- The creation of strategic partnerships among competitors and other stakeholders to push common suppliers and share the cost of some sustainability- related activities may be a key strategy for leveraging change within the music festival industry.

"One of our biggest challenges right now is convincing people that sustainability does not mean that we have to poo in dirt holes like hippies" -- Andrew Tatrai (Sustainability coordinator, Live Earth Australia) 


\section{Table 3.1. Template 1 - Needs}
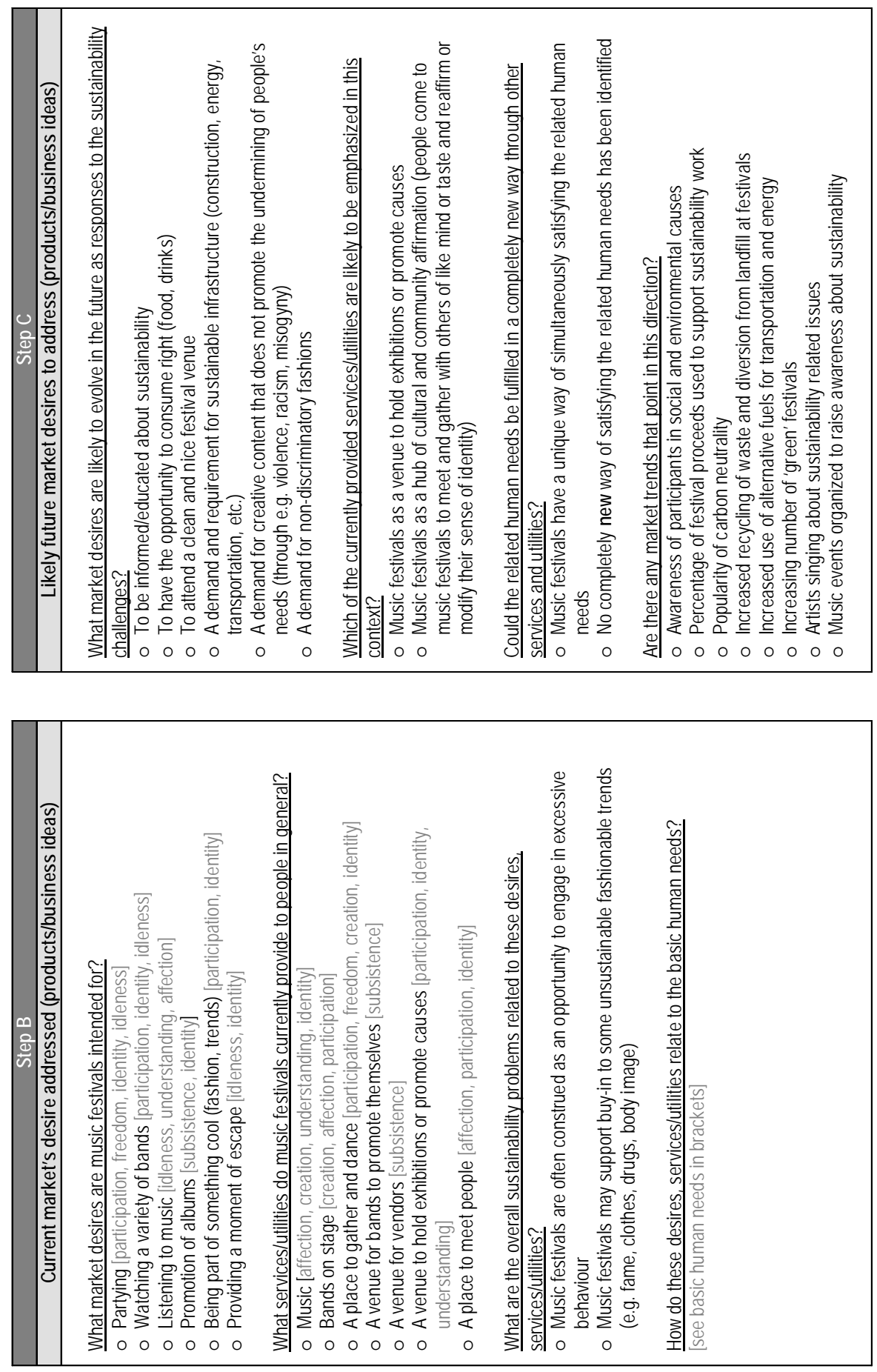
Table 3.2. Template 2 - Concepts
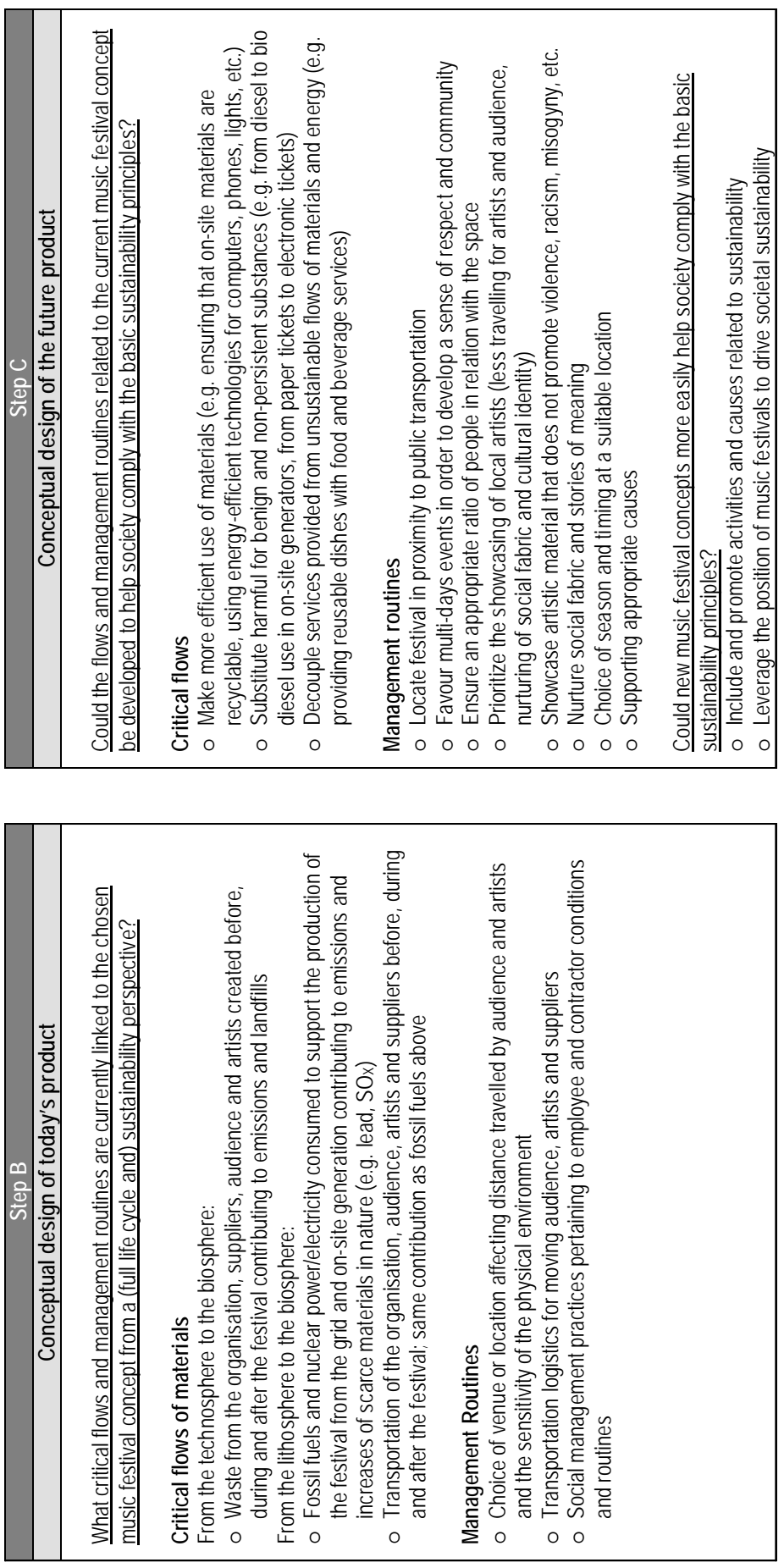
Table 3.3. Template 3 - Extended Enterprise
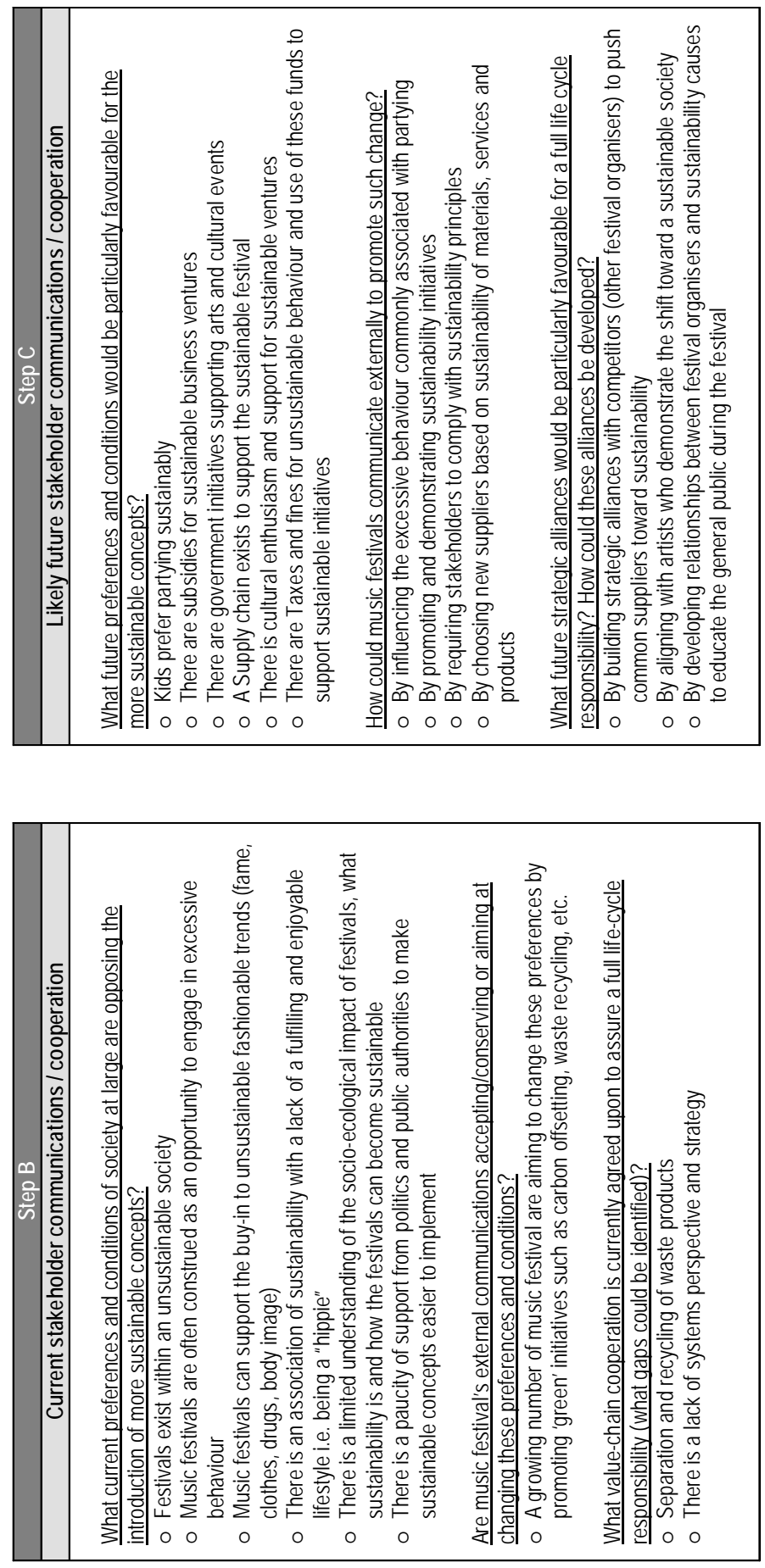


\subsection{Homebake: a case study}

\subsubsection{Vision exercise}

The first work we undertook with Homebake and IMC was an exercise designed to give us an understanding of what IMC's vision for Homebake is. The results of this are as follows, presented in the words of IMC's codirector, Tom Lang (2007).

Purpose of Homebake: To develop and promote Australian music to a broad audience and in turn help to promote and sustain a very talented local music industry.

Values:

1. All Antipodean music / arts festival. It is the only one [festival] of its kind in the country;

2. [To be] Held in a prime location in the middle of Sydney, at the Domain, the Botanic Gardens;

3. Each year, include a legendary band to give 'the kids' a little history lesson [in Australian musical history]; and

4. Each year...donate a percentage of Homebake's profits to a relevant youth-oriented charity.

\section{Strategic Goals:}

1. To continue being a major event on the ever-growing and ever-more competitive festival circuit;

2. To...expose new talent in a festival environment and help give up-and-coming artists another means of gaining attention at a national level;

3. [To] promote Australian bands at Homebake, helping those bands [find bookings] when they tour and the bands touring help promote the festival. Yin and yang!;

4. To use Homebake to launch Australian bands and the festival on the international market;

5. To have some grass still left in the middle of the city that has not died as a result of global warming and planet abuse;

6. To become an even more important part of Australian music history; and

7. To always be forward-thinking, developing and progressive. 
We had expected to receive a clear statement of values as part of the vision exercise, detailing the qualities that really give Homebake its personality. We did not receive this exactly (the final two values are actually actions), but the overall information gave us a good sense of the character and directions of Homebake.

Understanding the purpose, values and goals of Homebake before working through sustainability education sessions enabled us to better tailor our conversations with IMC. That is to say: it gave us a feel for the 'language' of Homebake. Due to this, we were able to modify our conversation so that it better reflected the unique identity of Homebake. Arguably, this created a richer working relationship than might have otherwise occurred, as IMC's tension around being judged and found wanted by a 'sustainability outfit' were dispelled from the beginning. The visioning exercise also stimulated the development of a draft generic vision that could be used as a starting point for festival organizers to create together a vision for sustainable music festivals.

\subsubsection{SWOT analysis}

We felt that the general conclusions that were drawn from the compilation of interviews, literature reviews and team-brainstorming needed to be corroborated. In order to better understand what it is that Homebake actually does - what it relies on, produces, and has left - we undertook a Strengths, Weaknesses, Opportunities and Threats (SWOT) analysis of the festival and its stakeholders (Figure 3.1). The full SWOT summary follows below (Figure 3.2 and Table 3.4 and 3.5).

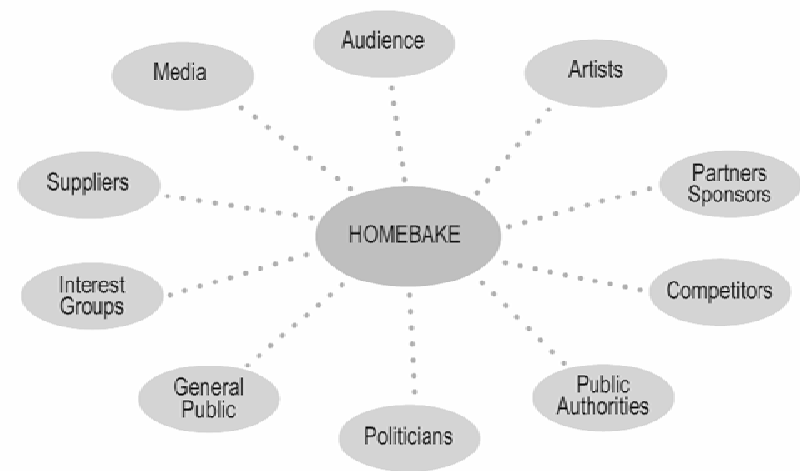

Figure 3.1. Homebake's stakeholders in the exterior world 
Table 3.4. Summarized results of the exterior world analysis

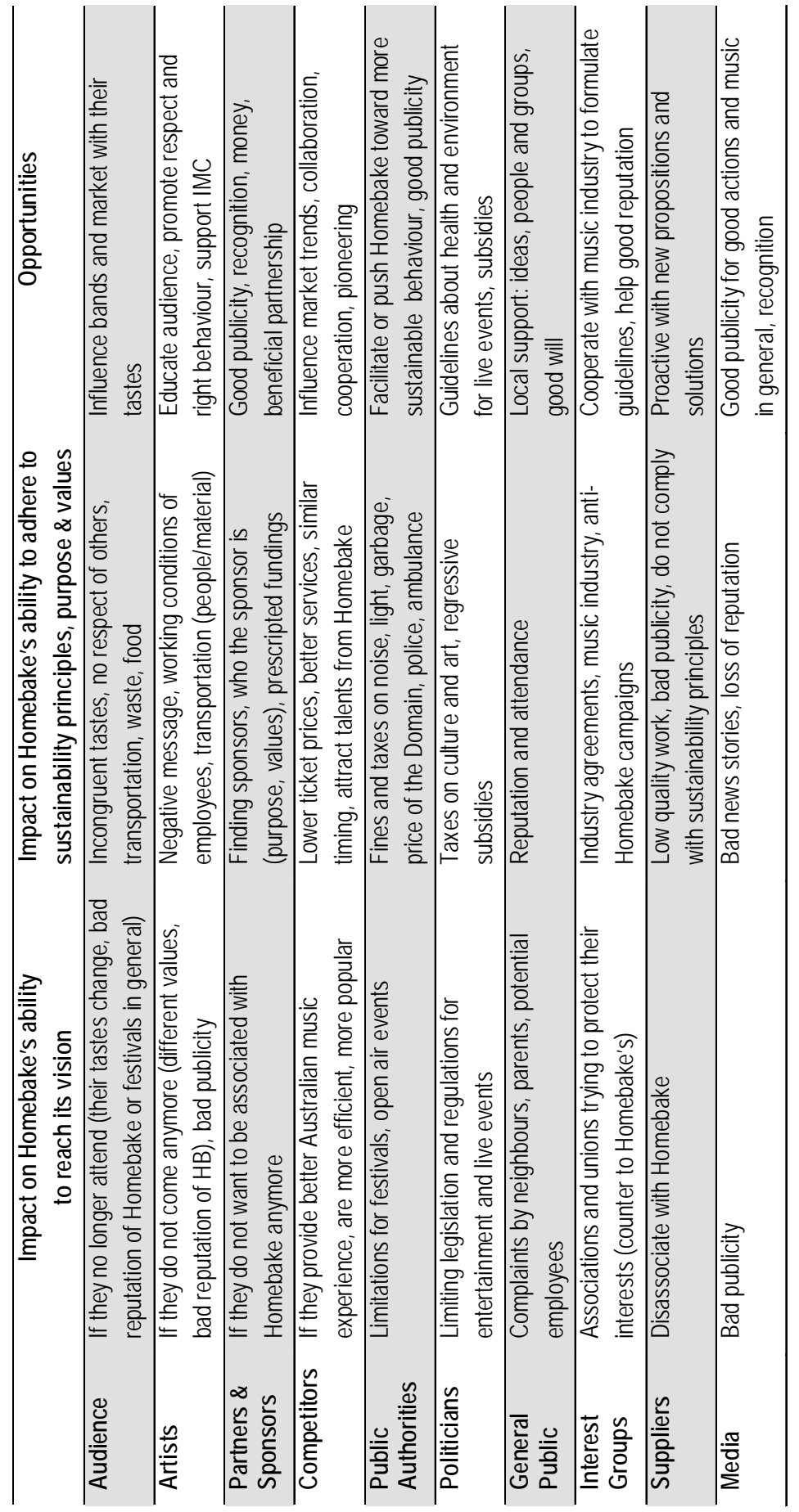




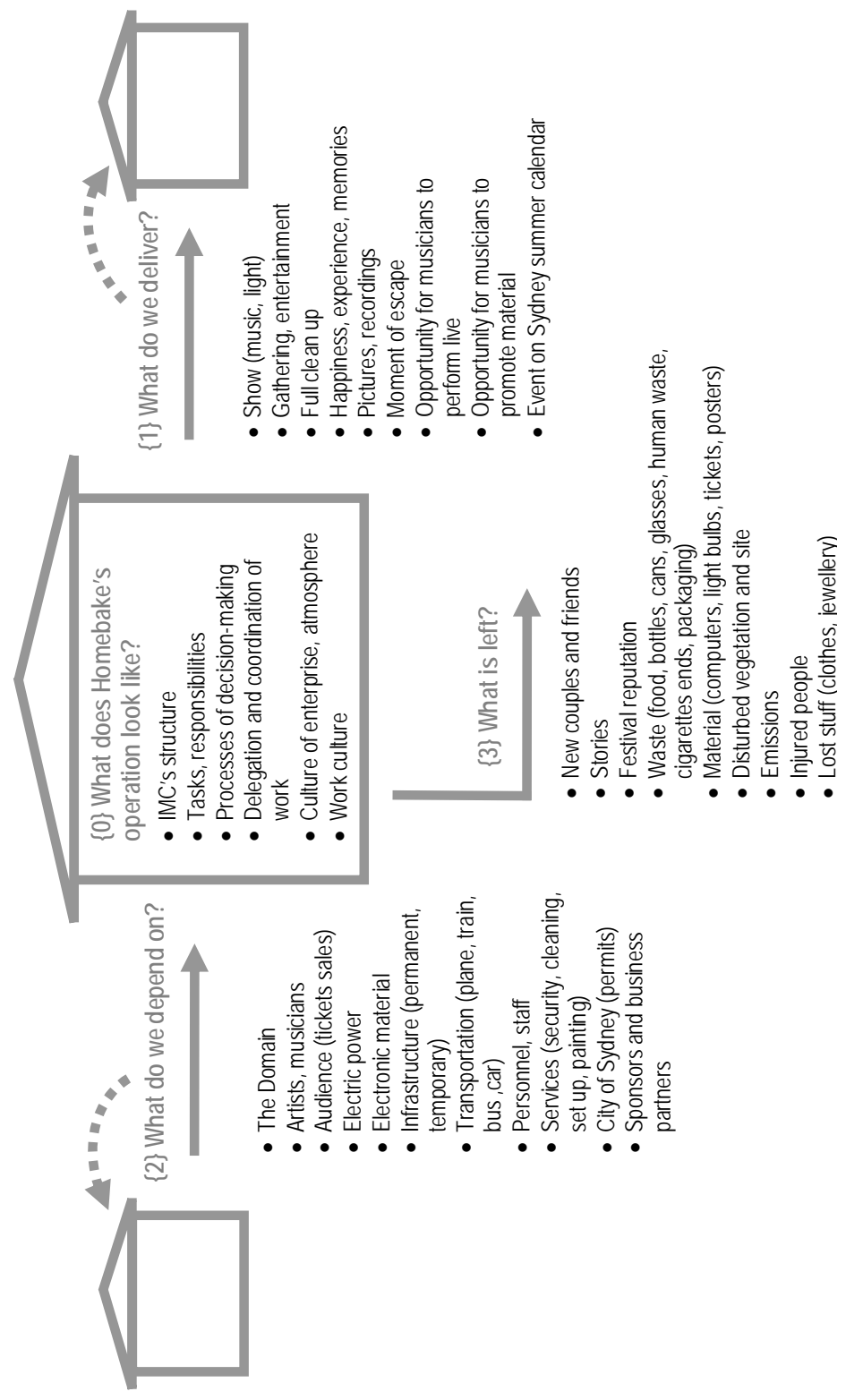

Figure 3.2. Model for the operational analysis of Homebake 
Table 3.5. Summarized results of the operational analysis

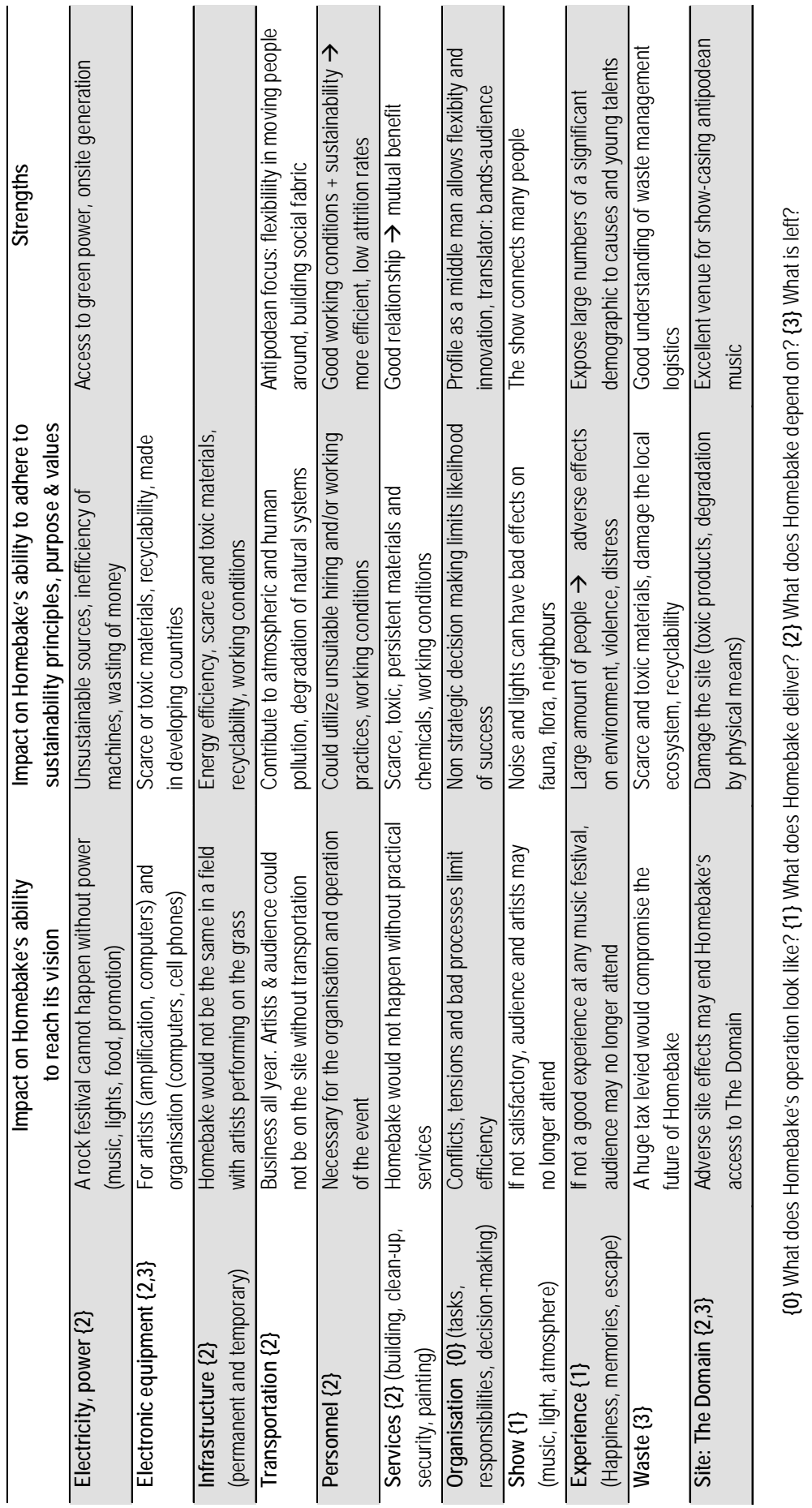


The SWOT elucidated many of the challenges and issues facing Homebake from a systems-sustainability perspective.

\subsubsection{ABCD workshop}

The results of the ABCD workshop are detailed below (Tables 3.6 and 3.7), and described for each system condition. Both assets and areas where Homebake could be in closer compliance with the sustainability principles are noted under each system condition. Chronologically, these tables were completed after the templates. After completing the ABCD workshop, we returned to the templates to scrutinize them against the results of the ABCD, refining the templates based on our deepened understanding of music festivals in general (Figure 2.3).

\subsubsection{Key findings}

The three general categories of results elaborated above -literature review and interviews, templates and the corroboration of these through the Homebake case study -combine to provide a powerful base of understanding of music festivals from a perspective of strategic sustainability. When viewed as a single body of information, there are a number of key findings that emerge:

- Music festivals occupy a particular niche in society, partially satisfying multiple basic human needs;

- The socio-ecological impacts of music festivals extend well beyond their spatial and temporal boundaries; many of these impacts are dependent on unsustainable flows of materials whose systematic use contributes to the undermining of social and natural systems;

- The role of the festival organizer is crucial from the perspective of strategic sustainability; the organization acts as a middle man for most of the material and social flows noted above. Thus as the organization shifts toward sustainability and the festivals it presents do too, there is massive potential to influence multiple stakeholders; and

- There are a few key stakeholders that are crucial to the success of a music festival. Most particularly, these are the artists; the audience; the suppliers; which include transportation suppliers, suppliers of 
on-site services and infrastructure and energy (power) providers; and the organization itself.

These findings are illustrated in the system map below (Figure 3.3). The map denotes critical flows of resources and dependencies affecting music festivals.

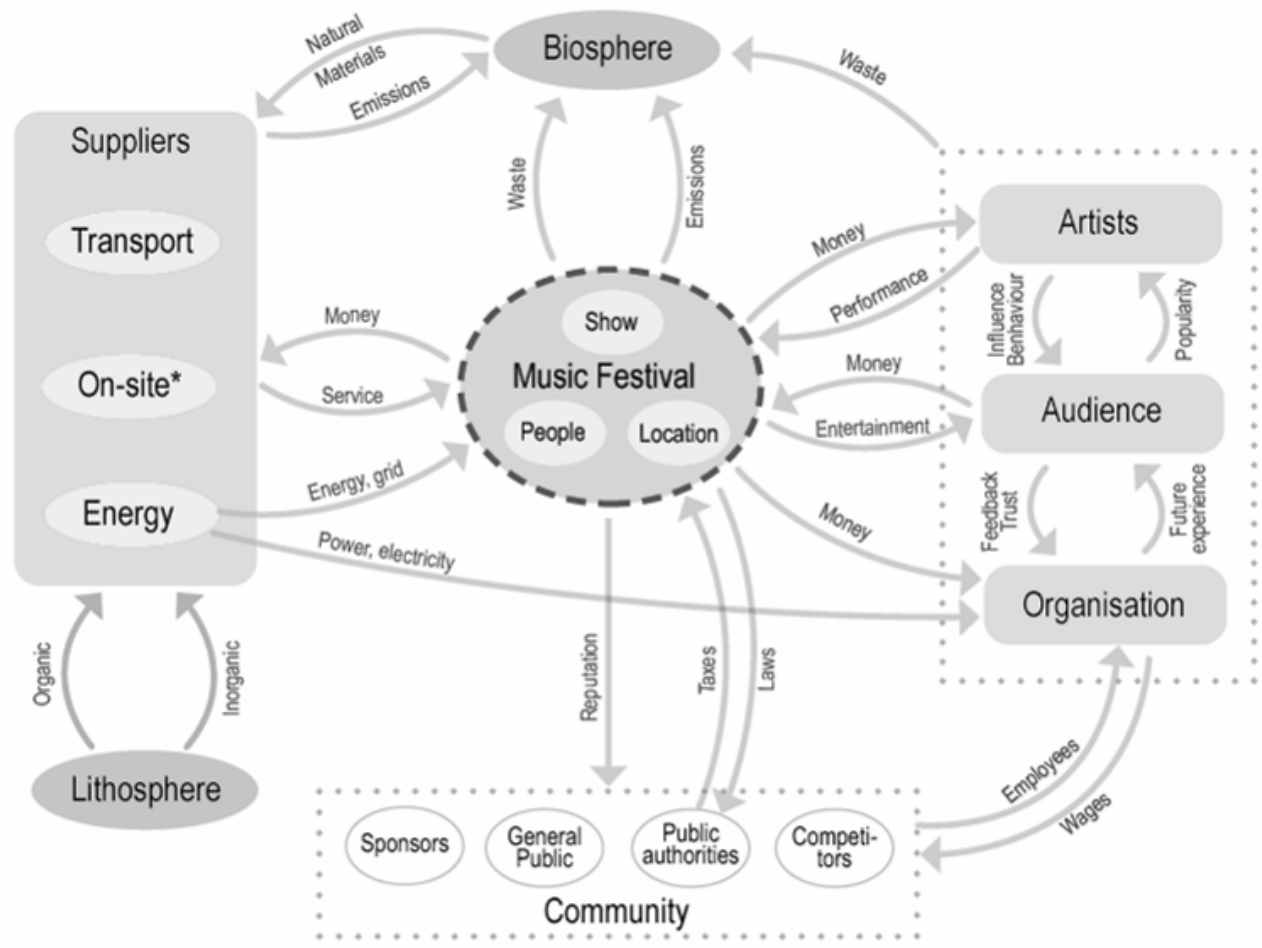

"The on-site suppliers include all the suppliers that are operating on the festival: vendors, security, infrastructure, cleaning, etc.

Figure 3.3. System map for music festivals, stakeholders and their interdependencies 
Table 3.6. B Step - Current situation

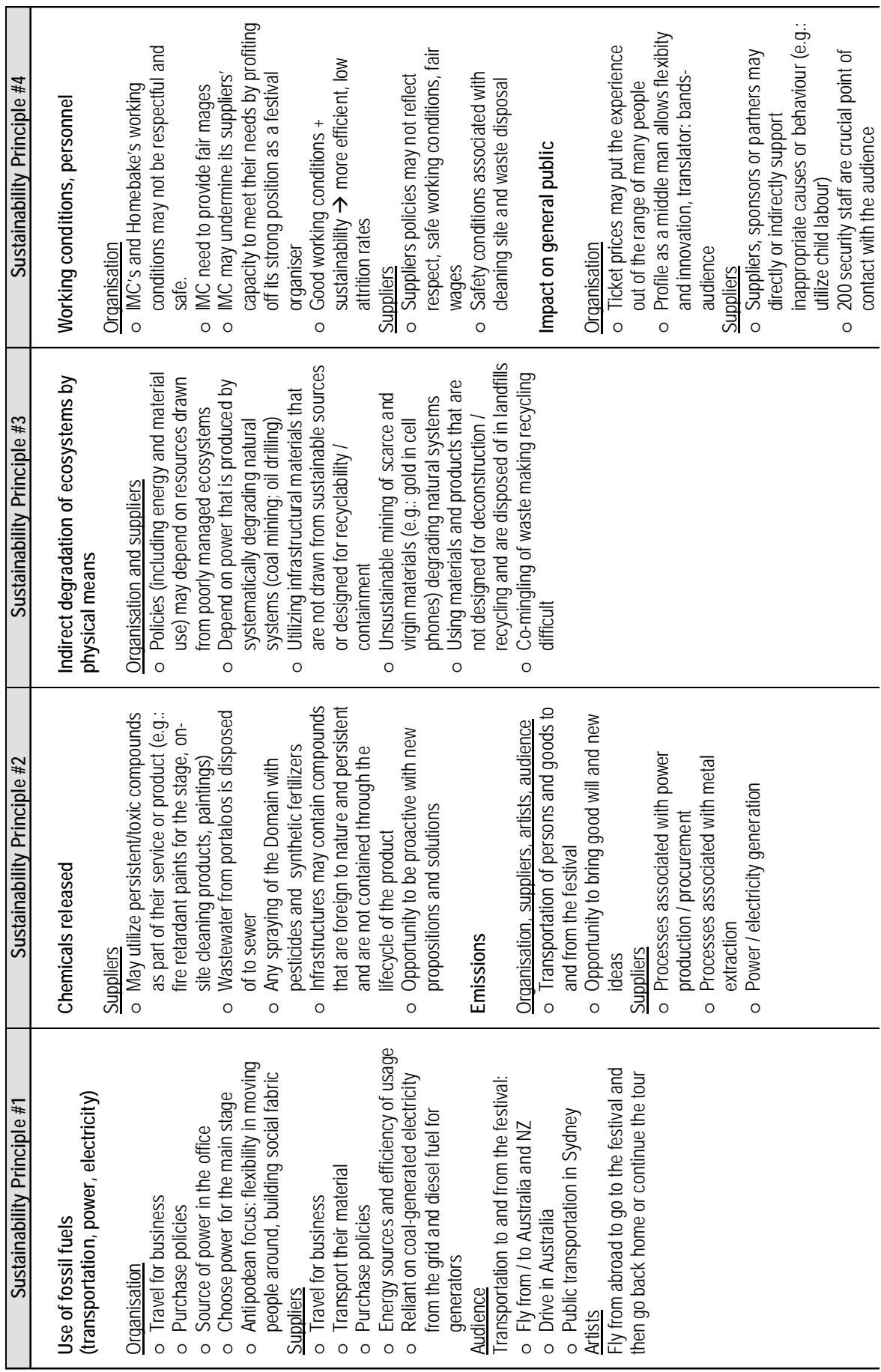




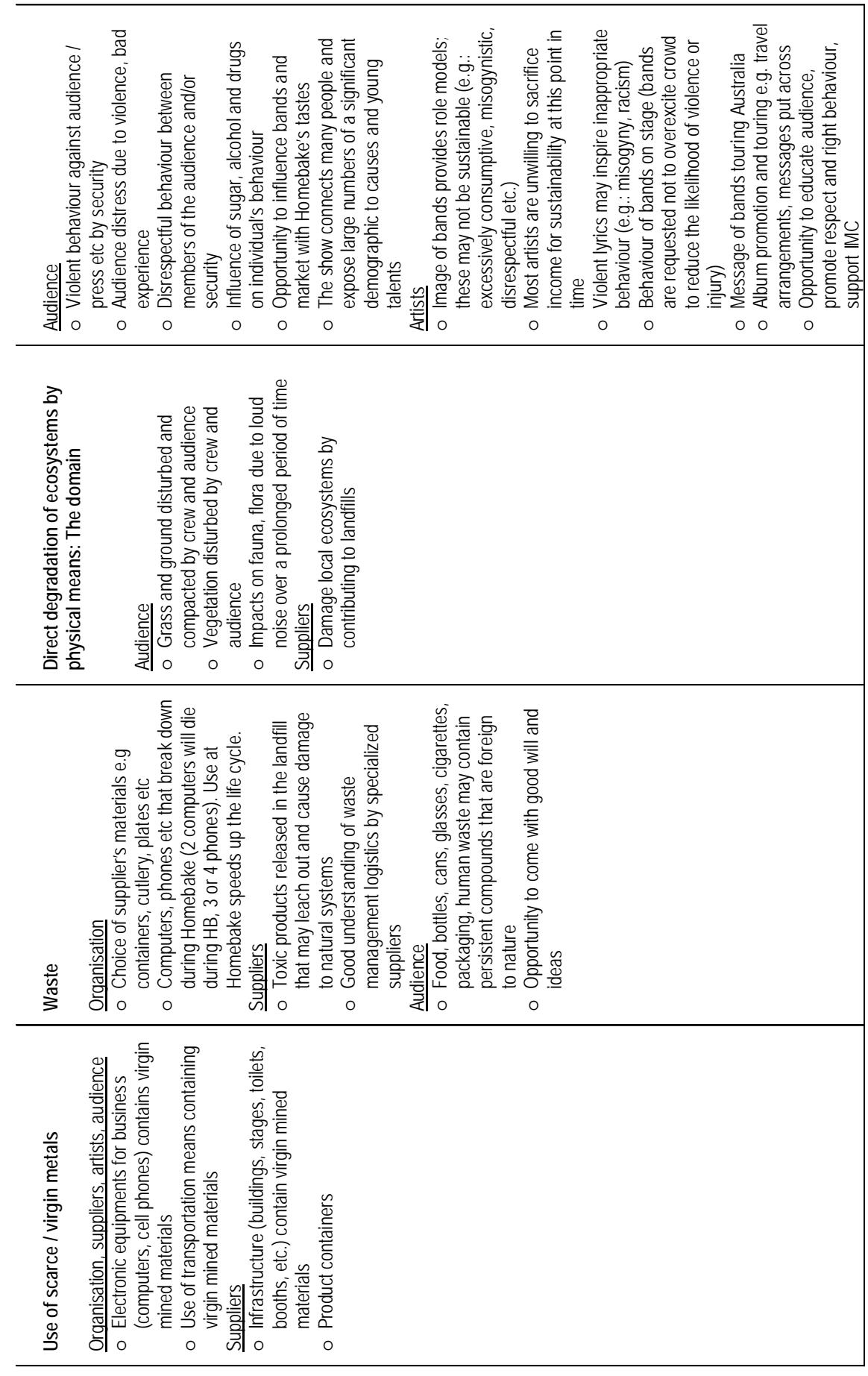


Table 3.7. C Step - Compelling measures (visioning, brainstorming)

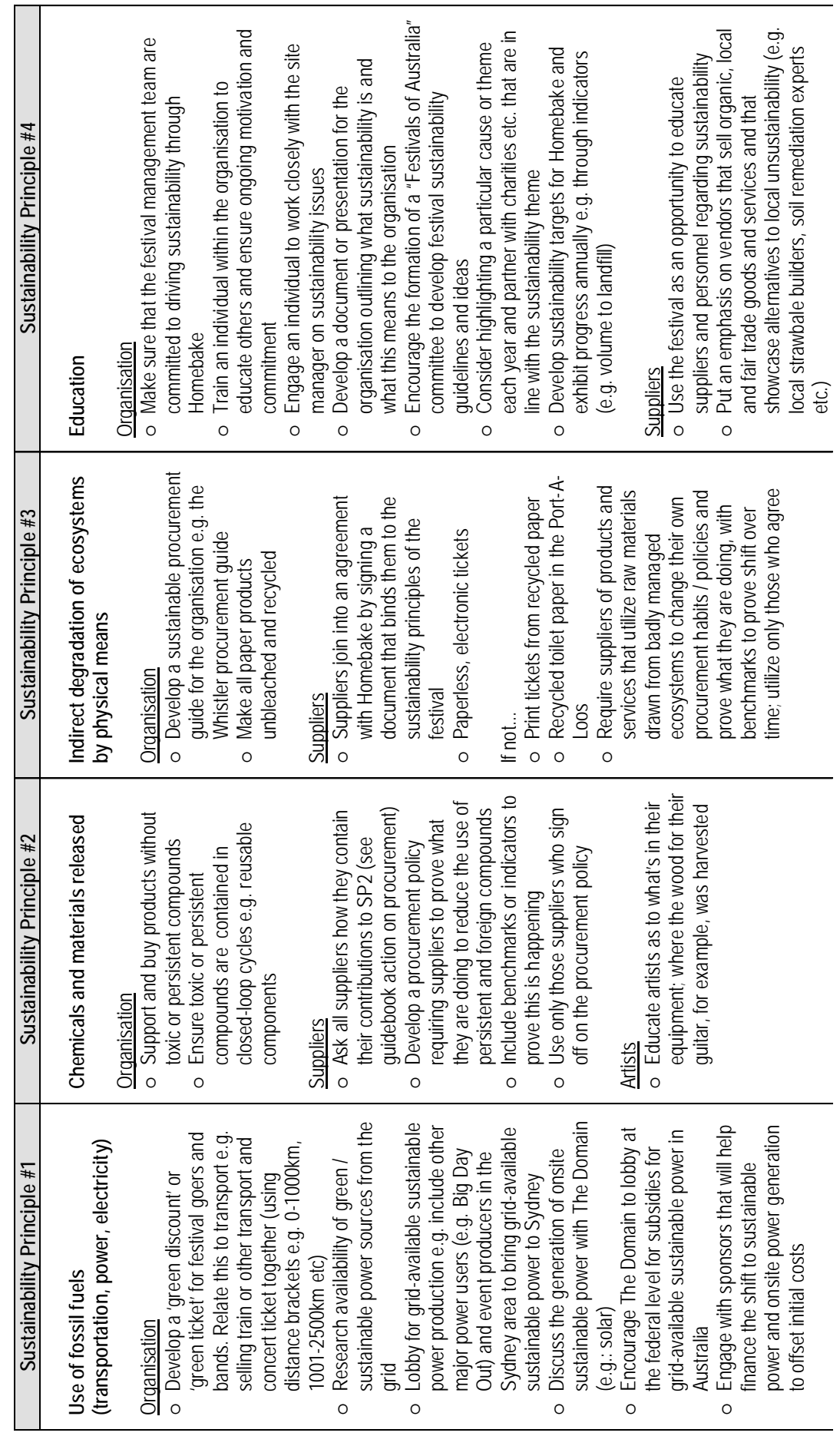




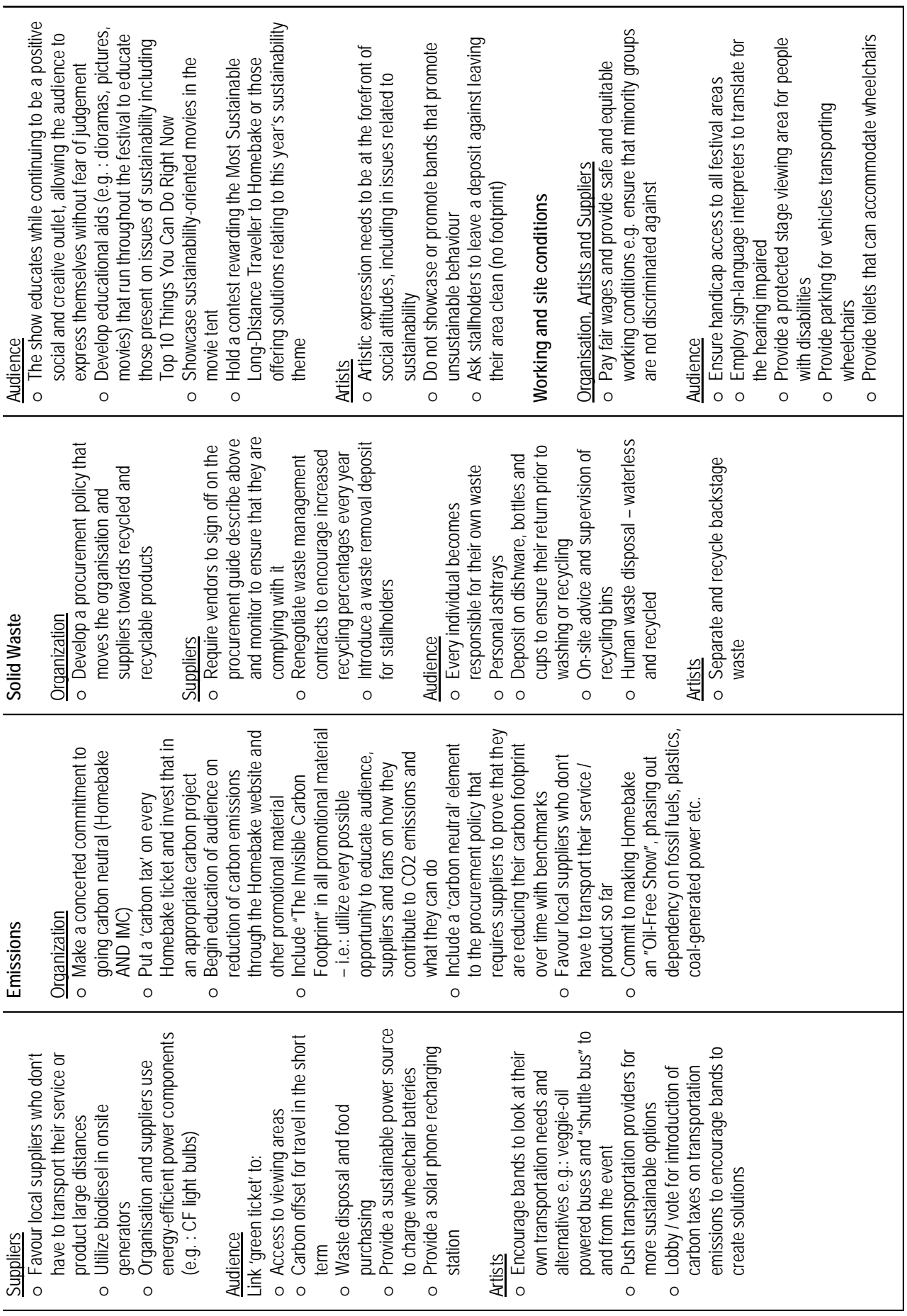


Further key findings include:

- Education is one of the most crucial factors in facilitating behavioural change that will shift music festivals toward sustainability. This includes education of parent organizations responsible for organizing and presenting music festivals; education of suppliers of services and products to music festivals; and education of the audience and artists as to how they can become more sustainable themselves. Education as to the nature of sustainability - what it is, why it must be and how it can be - and education as to how each stakeholder noted can be a partner in the reach for sustainability appear as two of the most crucial necessities and greatest opportunities to shift music festivals toward sustainability; and

- Music festivals cut a broad frontline across society and the communities in which they take place. They have, therefore, the opportunity not only to become more sustainable in themselves, but also to promote sustainability amongst these communities.

It is not, at this point, realistic to assume that every festival organizer who is interested in sustainability is going to make the effort to educate themselves. Their time is largely taken up with day-to-day details of running an organization. The greatest leverage point from a strategic point of view then, is to extend and make available any education developed from this research out to the larger festival industry. For this education to be useful, it must be communicated in such a way that it speaks to festival organizers. To this end, we take the results of our literature review, interviews, template and case study and channel the potential for change into a guidebook. This work is designed to help concerned festival organizers shift their events and the larger system within which they are embedded ('music festivals in society in the biosphere') toward sustainability.

\subsection{A guidebook for music festival organizers}

The music festival guidebook is designed to be a stand-alone document to assist music festival organizers transition their festival toward sustainability. 


\subsubsection{A capacity tool: generic and practical}

The guidebook itself is primarily a capacity tool that clearly relates the proposed actions to strategic goals to bring festivals closer to a vision of sustainability. It builds capacity and understanding by introducing the user to key sustainability concepts and regularly reminds the user of the festival's place in the system, or the biosphere.

The guidebook is written in generic terms to be applicable to music festivals generally, whilst proposing practical actions that can be implemented in line with broader strategies.

\subsubsection{A guidebook for a complex system}

The structure of the guidebook takes the reader systematically through the planning process by first describing, through systems maps, where the music festival sits within the broader social and ecological system. It then continues by offering a vision statement for the successful music festival.

The vision statement is drafted to inspire the festival organizer by describing what the music festival could represent in the sustainable society. Having considered the draft generic vision, the user is then introduced to sustainability's core concepts through an illustrated explanation of strategic sustainable development.

With a vision of success, knowledge of the festival's place in the broader system, and an understanding of what sustainability represents, the user is then introduced to a strategy to guide the festival toward sustainability.

\subsubsection{Strategic goals: the 6 strings of sustainability}

The guidebook proposes six challenging but achievable strategic goals, named here, metaphorically, the 6 strings of sustainability, to guide music festivals towards sustainability. Not unlike the 6 strings on a guitar the 6 strings of sustainability need to work in harmony for the music festival to become sustainable. Pursuing one or two strategic goals in isolation is not sufficient. Considering all six strategies towards sustainability allows plenty of room for creativity from the festival organizer. 
The first step in determining what the 6 strings should be was the development of system maps that identified the music festival's place in the system with its associated material flows and management issues. These were verified through the literature review, case study and interview processes. The 6 strings address the major challenges (i.e. education, waste, energy and transport, etc.) that were revealed in the system map (Figure 3.3) and that were also prominent points of discussion during the case study and interviews. Room is also left for festival organizers to create their own «signature goal». The thesis group cross-referenced the strategic goals with the four sustainability principles to ensure consistency.

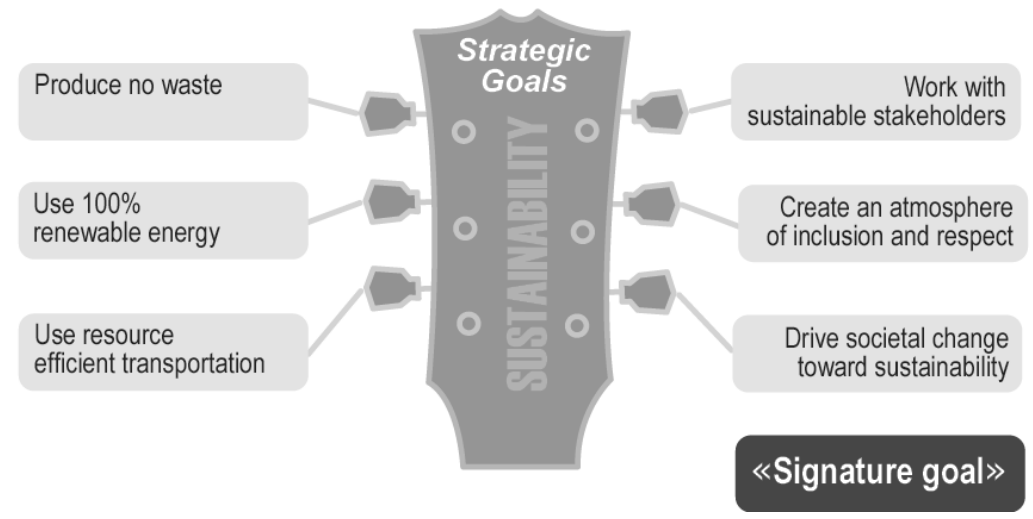

Figure 3.4. The 6 strings of sustainability for music festivals

The guidebook provides 12 actions that can be implemented at any music festival. Through the guidebook, the festival organizer can begin to understand how the actions contribute to achieving the strategy on the way to their vision of a sustainable music festival.

\subsubsection{2 actions -12 tones}

A total of twelve actions are described within the guidebook, with each action relating specifically to one of the strategic goals. As there are 12 tones on the musical scale, we have named our 12 actions the 12 tones. This metaphor is designed to emphasize that the actions presented are not hierarchical, in terms of either importance or prioritisation, and that they can be implemented, or played, together (Table 3.8). 
Table 3.8. The 12 tones - Strategic goals and their related actions

\begin{tabular}{|c|c|c|}
\hline The 6 strings & & The 12 tones \\
\hline Produce no waste & A & $\begin{array}{l}\text { Phase out all disposable food and beverage } \\
\text { containers }\end{array}$ \\
\hline \multirow[t]{2}{*}{ Use 100\% renewable energy } & $\mathrm{B}^{\mathrm{b}}$ & Implement an internal energy efficiency policy \\
\hline & $\mathrm{B}$ & $\begin{array}{l}\text { Develop strategic partnerships to access } \\
\text { renewable energy }\end{array}$ \\
\hline \multirow[t]{2}{*}{ Use resource efficient transportation } & $\mathrm{C}$ & Sell a new ticket that includes transportation \\
\hline & $\mathrm{C}^{\#}$ & Choose or change the location \\
\hline \multirow[t]{2}{*}{ Work with sustainable stakeholders } & $\mathrm{D}$ & Bring a sustainability coordinator on board \\
\hline & $D^{\#}$ & Introduce a procurement policy for suppliers \\
\hline \multirow{2}{*}{$\begin{array}{l}\text { Create an atmosphere of inclusion } \\
\text { and respect }\end{array}$} & $\mathrm{E}$ & Create areas for under-represented people \\
\hline & $\mathrm{F}$ & Go and speak with kids \\
\hline \multirow{3}{*}{$\begin{array}{l}\text { Drive societal change toward } \\
\text { sustainability }\end{array}$} & $\mathrm{F}^{\#}$ & Ask artists to DO ONE THING \\
\hline & G & $\begin{array}{l}\text { Include stalls and spaces that convey } \\
\text { sustainability ideas }\end{array}$ \\
\hline & $\mathrm{G}^{\#}$ & Generate ideas using your festival website \\
\hline
\end{tabular}

Within the guidebook, two facing pages are dedicated to each of the 12 tones or actions.

On the right hand side, each action is described in detail and is labelled according to a specific tone (e.g. A, $\mathrm{B}^{\mathrm{b}}, \mathrm{C}^{\#}$ etc). In the top right hand corner of the page, icons indicate which stakeholders the actions are likely to involve or affect.

Supporting actions are provided below this description that are aimed to complement or enhance the success of the given action. In addition there is a brief description of the expected results that a festival organizer can expect following the implementation of the action. 


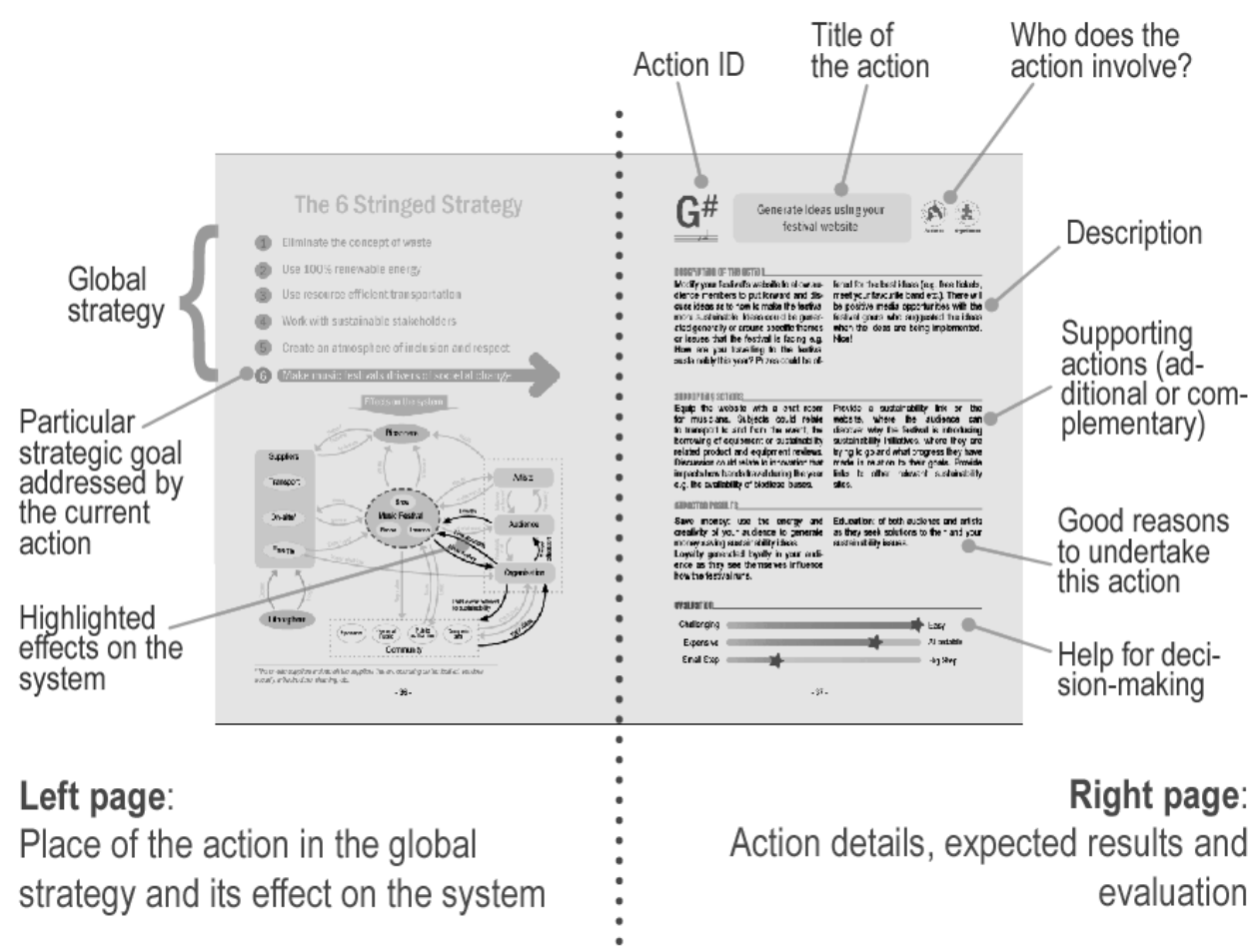

Figure 3.5. Two facing pages for each action in the guidebook

The left hand side is set out to remind the user which strategic goal the given action relates to. Beneath, a systems map illustrates where in the system the given action is likely to have an impact. It reminds us that music festivals exist within a broader system, and that achieving strategic goals relies upon interactions with that system. This provides the user with a systems perspective, reinforcing the core strategic sustainable development and systems thinking concepts.

Below the expected results are three scales, represented by horizontal bars, to indicate if the action is:

1. Difficult or easy;

2. Expensive or affordable; and

3. A small or big step towards sustainability.

These scales were designed to assist with, rather than complete, the prioritisation process, to give the festival organizer a sense of what to expect when undertaking one of the actions. 


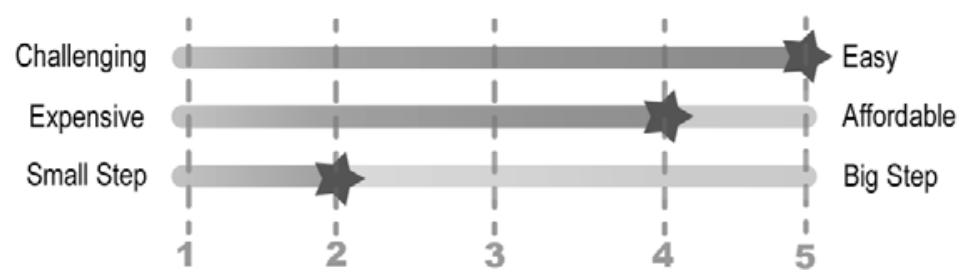

Figure 3.6. Scales to help the decision-making in the guidebook

Evaluation of each action was determined based on a relative ranking system where 1 is challenging, expensive and a small step toward sustainability and 5 is easy, affordable and a big step toward sustainability. The ranking system below resulted from brainstorming sessions within the thesis group where actions accorded most extreme rankings (1 or 5) relative to the other actions were identified first. Subsequent rankings were determined relative to these extremes.

This ranking system illustrates that actions were chosen to provide the organizers with options across a spectrum, allowing them to choose the actions most appropriate to their particular context.

Table 3.9. Action ranking system

\begin{tabular}{llccc}
\hline \multicolumn{1}{c}{ The 12 tones } & $\begin{array}{c}\text { Challengingl } \\
\text { Easy }\end{array}$ & $\begin{array}{c}\text { Expensivel } \\
\text { Affordable }\end{array}$ & $\begin{array}{c}\text { Smalll } \\
\text { Big Step }\end{array}$ \\
\hline A & $\begin{array}{l}\text { Phase out all disposable food and beverage } \\
\text { containers }\end{array}$ & 1 & 4 & 5 \\
\hline B $^{b}$ & Implement an internal energy efficiency policy & 5 & 5 & 2 \\
\hline B & $\begin{array}{l}\text { Develop strategic partnerships to access } \\
\text { renewable energy }\end{array}$ & 2 & 3 & 4 \\
\hline C & Sell a new ticket that includes transportation & 1 & 2 & 5 \\
\hline C\# & Choose or change the location & 2 & 3 & 4 \\
\hline D & Bring a sustainability coordinator on board & 4 & 2 & 4 \\
\hline D\# & Introduce a procurement policy for suppliers & 1 & 2 & 5 \\
\hline E & Create areas for under-represented people & 3 & 4 & 3 \\
\hline F & Go and speak with kids & 4 & 5 & 4 \\
\hline F\# & Ask artists to Do ONE THING & 5 & 4 & 3 \\
\hline G & $\begin{array}{l}\text { Include stalls and spaces that convey } \\
\text { sustainability ideas }\end{array}$ & 2 & 4 & 2 \\
\hline G\# & Generate ideas using your festival website & 5 & 5 \\
\hline
\end{tabular}


Two actions are suggested for each strategic goal, with two exceptions. One action is suggested under 'Produce no waste'. This is because our research shows that waste management is already a focus of attention for festival organizers looking to reduce their impacts. Also, the one action we propose, 'Phase out all disposable food and beverage containers', is intended to be a challenging goal to be implemented over time requiring a number of supporting actions.

The strategic goal, 'Drive societal change toward sustainability' has three related actions. During our research we began to appreciate the as yet unrealized influence that festivals, through the audience artists and suppliers, could have in moving society toward sustainability. As such we have focussed on this to help festival organizers see the very real potential they have to become sustainability leaders in the community.

Whilst the actions proposed within the guidebook are obviously not a comprehensive list, the guidebook is designed to trigger creativity and generate new ideas, so that the festival organizer can confidently come up with their own set of actions to achieve their strategic goals. 


\section{Discussion}

This section analyses and explores the implications of our research from the perspective of our research questions and strategic sustainable development. It also details the strengths and limitations of our results.

The research in this thesis was undertaken to explore solutions that can be applied to music festivals that will move them strategically toward sustainability. This required a compilation of existing information and also exploration of a territory largely undiscovered to date - that of a marriage between music festivals and strategic sustainability.

This discussion reviews the results of our research in relation to the research questions proposed in the introduction to the thesis document. It also explores the implications of our results.

\subsection{Primary research question}

What are some measures that can move music festivals strategically toward sustainability?

As detailed in the results section above, the music festival guidebook has been specifically designed to assist festival organizers transition towards sustainability. The foundation of this tool was the identification of common leverage points and challenges that many music festivals experience as they move toward sustainability.

Some of those leverage points and challenges identified were common to music festivals generally and warrant further discussion as we seek to understand, at a higher level, what measures could be applied to music festivals to move them toward sustainability.

Education: It was widely accepted that education and awareness in festival organizers, suppliers, audience and artists, posed the greatest challenge to music festival organizers. It was also identified as perhaps the greatest opportunity to affect change. Education runs through all of the major points discussed below. Indeed, it is required to create a shared vision and 
language for sustainability, from which a shared purpose can evolve. If the festival organizer is so educated, they can then use their role as 'middle man' to redefine their festivals goals and excite change in stakeholder groups.

Capacity building: Strongly related to Education above, the organization requires the capacity to strategically plan their actions with reference to their strategic goals. It is this capacity that breeds the confidence and enthusiasm to tackle the music festival's more significant challenges, increasing the likelihood of a sustainable outcome. For example, during the case study process the thesis group recognized IMC's growing enthusiasm as they became more familiar with key sustainability concepts and how these could be applied at the Homebake festival.

Those festivals that are making progress tend to have dedicated specific resources to the implementation of their 'green' initiatives. One festival organizer had hired a sustainability consultant who was beginning to show them how money could be saved, challenging a commonly held notion that sustainability is necessarily damaging to the financial bottom line (DuCrou 2007: pers. comm.).

Supply chain transformation: In its role as the 'middle man', the festival organizer is reliant on suppliers to achieve the festival's sustainability goals. Waste contractors, food and beverage vendors and energy and transport providers (to name a few), need to become part of the process to satisfy the requirements of the sustainable festival organizer.

At this point, internal capacity is critical, as the organizer needs to be able to express the festival's requirements to stakeholders in a language understandable to them. These requirements must also seem achievable in the short term, and beneficial in the longer term.

Formation of strategic alliances: Whilst there are a large and growing number of festivals held each year, the contractors and logistics operators that work on them are far fewer in number. For example, approximately only five contractors manage waste disposal at music festivals in all of New South Wales, Australia (Lang, 2007: pers. comm.).

Organizers can therefore consider combining their 'buying' power to influence the supply chain, clearly stating that 'this is the direction the 
industry is going'. Contractors need to know that this is a reality, that festival organizers are serious and that there will not be work for contractors who can't satisfy these requirements.

Political support: Lobbying government for political support can afford the festival organizer greater certainty in their sustainable development efforts. If definite regulatory or financial signals were sent to the market in support of sustainable development initiatives, then festival organizers and their supply chains could modify their operations with greater confidence. Therefore greater support and certainty in the short term may result in longer term success.

Realisation of Potential: There was a growing recognition amongst organizers of the potential music festivals have to bring the sustainability message to its stakeholders, notably the audience, artists and suppliers. This is both through its role as 'middle man', as discussed above, but also through the unique opportunity presented by gathering a large number of relatively like-minded individuals together to form a temporary community.

The notion that the message delivered at the music festival could resonate beyond that time and space to effect broader change is an exciting and very real opportunity that should be pursued.

"We have the ability to communicate to large numbers of people...and [at music festivals] people are open and receptive to new ideas!" - Jess DuCrou (manager, Splendour in the Grass)

Using music festivals to cultivate sustainability in industrialized countries is very new. Certainly there is a history of using music festivals to raise money for the so-called 'have-nots' of the world (think of the Live Aid concerts). Arguably, this is done with the intention of contributing to social sustainability, attempting to reduce the vast disparities between the wealthy and less wealthy areas of the world.

Four weeks into the development of this thesis, a series of 'Live Earth: concerts for a climate in crisis' music events were announced. The concerts are intended to occur on seven continents over a twenty-four hour period, and are hoped to trigger the launching of a global movement to combat climate change (Live Earth, 2007). We believe the timing is ripe to mobilize the music festival industry as a driver and partner of sustainable 
development. It could be of benefit to such a mobilization to develop an industry-wide framework to guide this shift and maximize the likelihood of arriving at sustainability. Because this is a nascent movement, it is a perfect opportunity to utilize strategic tools such as backcasting from sustainability principles to guide its progress.

"We all have to adopt these things [sustainability principles] from the word go and just say, 'this is how we operate'...when you take on new bands, you can let them know that this is the way you operate” - Tom Lang (co-director, IMC)

\section{Research strengths and limitations}

Our main response the primary research question was the development of a capacity tool i.e. the guidebook. This was decided in response to the results of the spiral learning (Figure 2.3) that occurred during the thesis period.

In general terms this illustrates the main strength of our research, namely that the outcomes of each research methodology fed into the others, such that the information gathered and presented in the guidebook was reviewed and validated.

Specific strengths and limitations of the research are dealt with under each of the relevant secondary questions below. The secondary research questions have been articulated to reflect the strategic sustainable development process which resulted in them being structured in a clear and logical manner.

\subsection{Secondary research questions}

What do music festivals look like now from a perspective of strategic sustainability?

When considered from a strategic sustainable development perspective, the challenges identified by music festival organizers today can be broadly characterized by:

1. Impacts of large numbers of people travelling to and from the event;

2. Material flows into and waste flows out of the event; and

3. Energy consumption during the event. 
The reasons these challenges were identified may be due to their visibility (e.g. waste management), social and ecological impacts (e.g. energy and transportation) or the growing urgency attached of some of these issues (e.g. energy and transportation and their relationship to climate change).

The existence of the issues was covered in detail within the case study, and it is evident that music festival organizers are beginning to respond to these challenges and understand their duty to manage their events responsibly (DuCrou, 2007: pers. comm.; Lang, 2007: pers. comm.; Rogers, 2007: pers. comm). Many organizers are beginning to implement 'green' initiatives, albeit to varying degrees. For example, waste separation and recycling facilities would seem to be a common feature, and some festivals have begun to look to carbon offsets to neutralize their contribution to climate change (DuCrou 2007, pers. comm.).

Successful festival organizers are also in tune with their audience's preferences, both in terms musical and social trends (Rogers 2007, pers. comm.). Therefore it may be suggested that the drive behind the 'greening' of music festivals in today's competitive market is due as much to the expectations of the paying audience as the personal commitment of the festival organizer.

Thus, while the music festival today has significant challenges on its road to sustainability, there is an enthusiasm and openness to new ideas in festival organizers that is cause for optimism.

\section{Research strengths and limitations}

At the commencement of our research it became evident that there was a scarcity of peer reviewed academic material specifically concerned with sustainability and music festivals. We therefore sought to get the most relevant and timely information regarding the current reality of music festivals from interviews and the case study.

The interviews gave us an insight into how music festival organizers perceive sustainability and the challenges they faced from this perspective. Although the interviewees do not constitute a representative sample, general conclusions were drawn that were consistent with the more detailed results from the case study. 
The case study was undertaken using backcasting and the four steps of the ABCD process. This provided a comprehensive understanding of the Homebake festival. The A step (i.e. awareness) presentation given to IMC resulted in a shared mental upon which to build our shared understanding of sustainability.

One of the first case study exercises to determine the purpose, values and goals for Homebake, was undertaken without a clear understanding of each of these terms. Following the exercise, we clarified the definitions for each with IMC and focussed our attention on those responses that were aligned with those definitions.

While the case study was undertaken with one of the two key personal at IMC, the initial thoroughness and review of the B step and SWOT analysis left us confident that no important details were omitted.

\section{What do music festivals look like in a sustainable society?}

The music festival is a unique occasion that satisfies a variety of needs simultaneously. When considering the human needs that the festival satisfies, it was difficult to imagine a completely 'new' way for these same needs to be satisfied as effectively. Therefore, we resolved that the essence of the music festival is here to stay and focussed on transforming those elements that challenge its movement toward sustainability.

The draft generic vision of the sustainable music festival (contained within the guidebook document), reflects the opinions of interviewees and in particular IMC's vision for Homebake that was discussed at length during the case study activities.

Without repeating our vision statement in its entirety, it focuses on what the music festival could mean to artists, audience and the society where the event is held. It emphasizes that music festivals are an integral part of a community that embraces new attitudes and ideas, whilst remaining a place for fun where artistic expression (is) experienced joyfully in an atmosphere of safety and mutual respect. 
Another crucial aspect of the vision includes the music festival drawing on the energy and creativity of organizers, suppliers, artists and audience as it continues to produce a sustainable event. This implies continual improvement, particularly in the way that the services that support the festival are delivered, with particular reference to closing material loops, sourcing sustainable energy, and making transportation clean and efficient.

All this is achievable in our vision with the festival continuing to be financially viable by attracting a large audience from a broad cross-section of the community. The vision is intended to be a starting point from which festival organizers can, together, create a vision for their sustainable music festival.

\section{Research strengths and limitations}

The first step in determining what festivals look like in the sustainable society was the completion of the template. The template was invaluable for the thesis group's understanding of music festivals, particularly during subsequent case study exercises such as the vision and C Step of the ABCD.

The original template was designed for sustainable product development purposes. We made minor changes to better accommodate a discussion on music festivals. These changes have been reviewed by academic staff however the template itself is yet to be reviewed by festival organizers.

How can we close the gap between music festivals now and in the sustainable society?

Having gained an appreciation of how music festivals are run today and developed a sustainable vision, we can better understand the gap that exists between the two. The case study, interviews and template development provided valuable insights into the greatest challenges facing festival organizers and the methods by which these are currently being tackled.

We have discovered that festival organizers recognize the need to transform their festivals in some way as they become aware of their responsibilities. Indeed, a number of admirable efforts and attitudes amongst festival organizers have been noted through this research. Without detracting from these efforts, it can be asserted that music festival organizers implement ad hoc measures in response to their most visible environmental challenges 
(e.g. waste), or chosen solutions that reflect the trends of the day (e.g. carbon offsetting in response to climate change). This tendency toward reactivity belies the existence of a strategic path toward sustainability.

Whilst the recognition of responsibility and subsequent action are commendable first steps, we have maintained our encouragement of organizations to look more at their challenges more strategically.

It was with this recognition that the research group developed a guidebook that could:

- Introduce the user to the core strategic sustainable development concepts;

- Illustrate clearly where the music festival sits within broader socioecological cycles (including both material flows and organizational management);

- Provide a draft generic vision for sustainable music festivals to inspire the user to action;

- Articulate strategic goals to guide festival organizers toward that vision; and

- Suggest possible actions that the festival organizer could implement, or that would serve to trigger creativity in developing other courses of action.

The guidebook is designed to reaffirm the relationship between the proposed actions and a) the festival's strategic goals and b) how these actions affect other flows and stakeholders within the broader system. In so doing, we aim to trigger the creativity of festival organizers, helping them to think about sustainable development from a systems perspective and find relevant and strategic solutions to their own issues.

The guidebook can also be used by other stakeholders in the system. For example, a venue or public authority (that manages open parkland where a festival may be held) may adopt the guidebook. They could insist that festival or event organizers implement the six strategic goals and prove that they are implementing actions in accordance with those goals. In this way, stakeholders can work together with a common understanding of what sustainability is. 


\section{Research strengths and limitations}

We believe the guidebook successfully integrates meaningful music festival industry input into a capacity tool that is presented in a clear, appealing and engaging way. It addresses the capacity and education issues discovered during the research, such as the lack of a shared definition of sustainability.

As we write, the guidebook is being critically reviewed by music festival organizers.

The D step of the ABCD process, i.e. the prioritisation of actions, was out of the scope of the thesis. We believe that this exercise could not be completed satisfactorily within the time restraints of the thesis, and without the specific business and financial information required. Direction on how to prioritize based on the framework for strategic sustainable development is provided in the guidebook.

Time constraints are a reality of academic studies, and although we had to stop somewhere, we could clearly have continued our dialogue with IMC and other festival organizers. We look forward to doing so in the future. 


\section{Conclusion}

The world is at a critical juncture. Daily, increasing attention is paid to social injustices and environmental degradation. The drive toward socioecological sustainability currently tends to focus on high-impact, high visibility industries such as forestry and oil and gas. The work of this thesis centres on bringing sustainability to an industry less familiar to this type of focus.

Recreational events gather large numbers of people in concentrated areas for brief periods of time. Effects of these events extend far beyond their spatial and temporal boundaries; a music festival is one such event. This paper asks, "What are some measures that can move music festivals strategically toward sustainability?” A framework for strategic sustainable development based on backcasting from sustainability principles is applied. Research draws on pertinent literature, interviews with festival organizers and an in-depth case study with International Music Concepts.

Results indicate that critical flows and management routines upon which music festivals depend contribute to the systematic undermining of social and ecological systems. Festival organizers sit at the centre of these flows, and are crucial to changing them. Education to inspire behavioural change of festival organizers and other stakeholders, notably suppliers, audience and artists, appears critical to shifting music festivals toward sustainability. This can be underpinned by building in-house 'sustainability capacity' of festival organisations; creating strategic alliances between festival organizers to push their common supply chain; and scaling up organisational efforts to include lobbying governments for financial and other support to authenticate a high-level commitment to sustainable development. Music festivals may then leverage their role in society to move society itself toward sustainability. A template and guidebook are presented to facilitate this shift. 


\section{Further research}

We hope this work will be a useful contribution to the dialectic of strategic sustainable development. We see it as timely research that would benefit from further development in many areas. These include:

1. Broadening the base of interviewees to include a more diverse range of festivals (including classical and jazz festivals, for example), and also a more global perspective for the work as a whole. This would reveal or confirm patterns and characteristics identified herein to modify and / or develop. It may also begin to point to ways to affect change within the events industry in general;

2. Disseminating, receiving feedback on and modifying the template in collaboration with festival organizers. This is largely an issue of time. Undertaking this would ensure that our work was even more collaborative and relevant to those for whom it is intended; and

3. Disseminating, receiving feedback on and expanding or otherwise modifying the guidebook. This involves multiple areas of focus, including: (a) working more closely with site managers and key suppliers to make the actions in the guidebook that pertain to affecting change through the festival's supply chain speak even more strongly to the stakeholders the actions are intended to affect; (b) making extensive connections with artists and exploring the leverage point(s) of involving artists to drive festivals toward sustainability; (c) involving festival organizers from all parts of the world to test to guidebook. This would help us discover whether or not this work is truly applicable around all curves of the planet - can the guidebook be used to success as well in Accra as it can in Sydney?

In my dream, the angel shrugged and said, If we fail this time, it will be a failure of imagination and then she placed the world gently in the palm of my hand. -- Brian Andreas, Imagining World 


\section{References}

Berlemann, Birte and Mitchell Rhodes. 2005. Sustainable IOC -

Sustainable Society. Master's thesis. Published at Blekinge

Institute of Technology: Karlskrona.

Broman, Göran I., Sophie Byggeth and Kalr-Henrik Robèrt. 2002.

Integrating Environmental Aspects into Engineering Education.

International Journal of Engineering Education. Volume 18,

Number 6. pp. 717-724.

British Petroleum. 2007. Facing the Issues: taking action to make a positive difference. Published online at

http://www.bp.com/productlanding.do?categoryId=4520\&contentId =7014704. Accessed 03 April.

Burr, Michael T. 2006. Facing the Climate Challenge. Public Utilities Fortnightly. Volume 144, Number 6. p. 3.

DuCrou, Jessica. 2007. Personal Communication. 02 April.

Dias, Rubens A., Cristiano R. Mattos and José A.P. Balestieri. 2006. The Limits of Human Development and the Use of Energy and Natural Resources. Energy Policy. Volume 34, Issue 9. pp 1026-1031.

Ehrlich, Robèrt. 2006. The Mother of All Threats? Across the Board. Volume 43, Issue 1. p. 11.

Globe Editorial. 2007. Hot on the environment, and willing to sacrifice. The Globe and Mail. January 27. Published online at www.theglobeandmail.com

Greenpeace. 2007. Stop Climate Change and Save the Boreal Forest.

Published online at http://www.greenpeace.org/canada/en/campaigns

Hall, Rebekah A. 2002. Feeling the Vibes. Waste Age. Volume 33, Issue 11. p 10. 
Harvey, L.D. Danny. 2004. Declining Temporal Effectiveness of Carbon Sequestration: Implications for compliance with the United National Framework Convention on Climate Change. Climactic Change. Volume 63, Issue 3. pp 259-290.

Holmberg, John and Karl-Henrik Robèrt. 2000. Backcasting from nonoverlapping sustainability principles - a framework for strategic planning. International Journal of Sustainable Development and World Ecology. Volume 7. pp. 291-308.

Holmberg, J., K.-H. Robèrt, and K.-E. Eriksson. 1996. Socio-ecological principles for sustainability. In Getting Down to Earth — Practical Applications of Ecological Economics, International Society of Ecological Economics, edited by R. Costanza, et al. Washington DC, USA.

Holmberg, J. and K.-H. Robèrt. 2000. Backcasting - a framework for strategic planning. International Journal of Sustainable Development and World Ecology. Volume 7. Issue 4. pp 291-308.

IPCC. 2007. Climate Change 2007: The Physical Science Basis. Summary for Policy Makers. The Intergovernmental Panel on Climate Change. IPCC Secretariat: Geneva.

James, Sarah and Tobjörn Lahti. 2004. The Natural Step for Communities: how cities and towns can change to sustainable practices. Gabriola Island, British Columbia, Canada: New Society Publishers.

Kaufman, Gill. 2006. Trashy Festivals? Not Anymore: Warped, Lollapalooza, Bonnaroo go green. Published online at http://www.mtv.com/news/articles/1533297/05312006/id_0.jhtml?h eadlines=true Accessed 09 February 2007.

Lang, Tom. 2007. Personal communication. 15 February, 05, 22, 29, 30 March, 03 April.

Leverentz, Harold and Mark Van Horn. 1999. Minimizing Festival Trash. Biocycle. Volume 40, Issue 9. pp. 45-48.

Live Earth website. www.liveearth.org. Accessed 22 March 2007. 
Max-Neef, Manfred. 1992. Human Scale Development: Conceptions, applications and further reflections. London: The Apex press

Maxwell, Joseph A. 2005. Qualitative Research Design. 2nd Edition. Sage Publications.

Mittelstaedt, Martin. 2007. The Fallout from Global Warming: 1,000 years. The Globe and Mail. 14 February.

Nattrass, B. and Mary Altomare. 2002. Dancing with the Tiger. Gabriola Island, British Columbia, Canada: New Society Publishers.

Ny, Henrik. 2006. Strategic Life-Cycle Modeling for Sustainable Product Development. Licentiate thesis, Department of Mechanical Engineering, Blekinge Institute of Technology, SE-371 79 Karlskrona, Sweden.

Ny, Henrik, S.H. Byggeth, J.P. MacDonald, K.-H. Robèrt. 2006. Introducing templates for sustainable product development through a case study of televisions at Matsushita Electric Group. Department of Mechanical Engineering, Blekinge Institute of Technology, SE371 79, Karlskrona, Sweden.

The Olympic Board. 2006. Towards a Sustainable Games. Published online at www.london2012.org/en/ourvision/greengames. Accessed 15 February 2007.

Resort Municipality of Whistler. 2007. Whistler, It's our Future. www.whistler.ca. Accessed 02 May, 2007.

Robèrt, Karl-Henrik, H.E. Daly, P.A. Hawken and J. Holmberg. 1997. A compass for sustainable development. International Journal of Sustainable Development and World Ecology. Volume 4. pp. 79-92

Robèrt, Karl-Henrik. 2002. Matsushita sustainability report - TVs and refrigerators (international Matsushita report). Stockholm: The Natural Step International.

Robèrt, Karl-Henrik, B. Schimdt-Bleek, J. Aloisi de Larderel, G. Basile, J.L. Jansen, R. Kuehr, P. Price Thomas, M. Suzuki, P. Hawken and M. Wackernagel. 2002. Strategic sustainable development - selection, 
design and synergy of applied tools. Journal of Cleaner Production. Volume 10. Issue 3. pp197-214.

Robèrt, Karl-Henrik et.al. 2006. Strategic Leadership Towards

Sustainability. Blekinge Institute of Technology: Karlskrona.

Rossmorris, Hannah. UK Festivals Clean Up Their Act. Published online at www.agreenerfestival.com. Accessed 09 February 13, 2007.

Sen, Z. 2004. Solar Energy in Progress and Future Research Trends. Progress in Energy and Combustion Science. Volume 30, Issue 4. pp. 367-416.

Steffen, W. et al. 2004. Global Change and the Earth System: a planet under pressure. Executive summary. Stockholm : IGPB Secretariat, Royal Academy of Swedish Sciences.

Stern Review Executive Summary (Full). 2007. Published online at http://www.hmtreasury.gov.uk/media/8AC/F7/Executive_Summary.pdf. Accessed 03 April. p. iii.

Stern Review Final Report. www.sternreview.org.uk. Accessed 23 March 2007.

The Shelter Awards for Social Sustainability 2006. Published online at http://www.virtualfestivals.com/awards/2006/index.cfm?action=cate gory\&id=19 Accessed 09 February 2007.

The Natural Step. 2007. Published online at http://www.naturalstep.org. Accessed 16 February 2007.

The Natural Step Canada. 2007. Published online at www.naturalstep.ca

Timo, Tohmo. 2005. Economic impacts of cultural events on local economies: an input-output analysis of the Kaustinen Folk Music Festival. Tourism Economics. Volume 11, Issue 3. pp 143+.

United Nations Millenium Development Goals. 2007. Keep the Promise, 2015. Published online at http://www.un.org/millenniumgoals/. Accessed 26 March. 
United Nations Statistics Division. 2007. Millenium Development Goals Indicators. Published online at http://mdgs.un.org/unsd/mdg/Host.aspx?Content=Data/Trends.htm. Accessed 15 February 2007.

Van Shagan, Sarah. 2007. Live Earth Concerts Official. Published online on Grist http://gristmill.grist.org/story/2007/2/15/114914/856. Accessed 16 February.

Velisarios, Kattoulas. 2001. Crime and the city. Far Eastern Economic Review. Volume 164, Issue 45. pp. 60-64.

Vider, Stephen. 2004. Rethinking Crowd Violence: Self-categorization theory and the 1999 Woodstock riot. Journal for the Theory of Social Behaviour. Volume 34 Issue 2. pp 141-166.

WCED. 1987. Our Common Future. The World Commission on Environment and Development. Oxford University Press: Oxford.

Western Canadian Wilderness Committee. 2007. Clayoquot Sound Headed for Conflict Once Again. Published online at http://www.wildernesscommittee.org/. Accessed 03 April.

Willard, Bob. 2005. The NEXT Sustainability Wave. New Society Publishers: Gabriola Island, BC.

World Bank. 2007. On World Environment Day - World Bank Group Goes Carbon Neutral. Published online at http://web.worldbank.org/WBSITE/EXTERNAL/TOPICS/ENVIR ONMENT/0,,contentMDK:20945328 menuPK:242147 pagePK:64 020865 piPK:149114 theSitePK:244381,00.html. Accessed 19 February.

World Wildlife Fund. 2005. Hot, Hungry and Gasping for Air:our fishare at risk, warns WWF. Published online at http://www.wwf.org.nz/. Accessed 03 April. 


\section{Appendix}

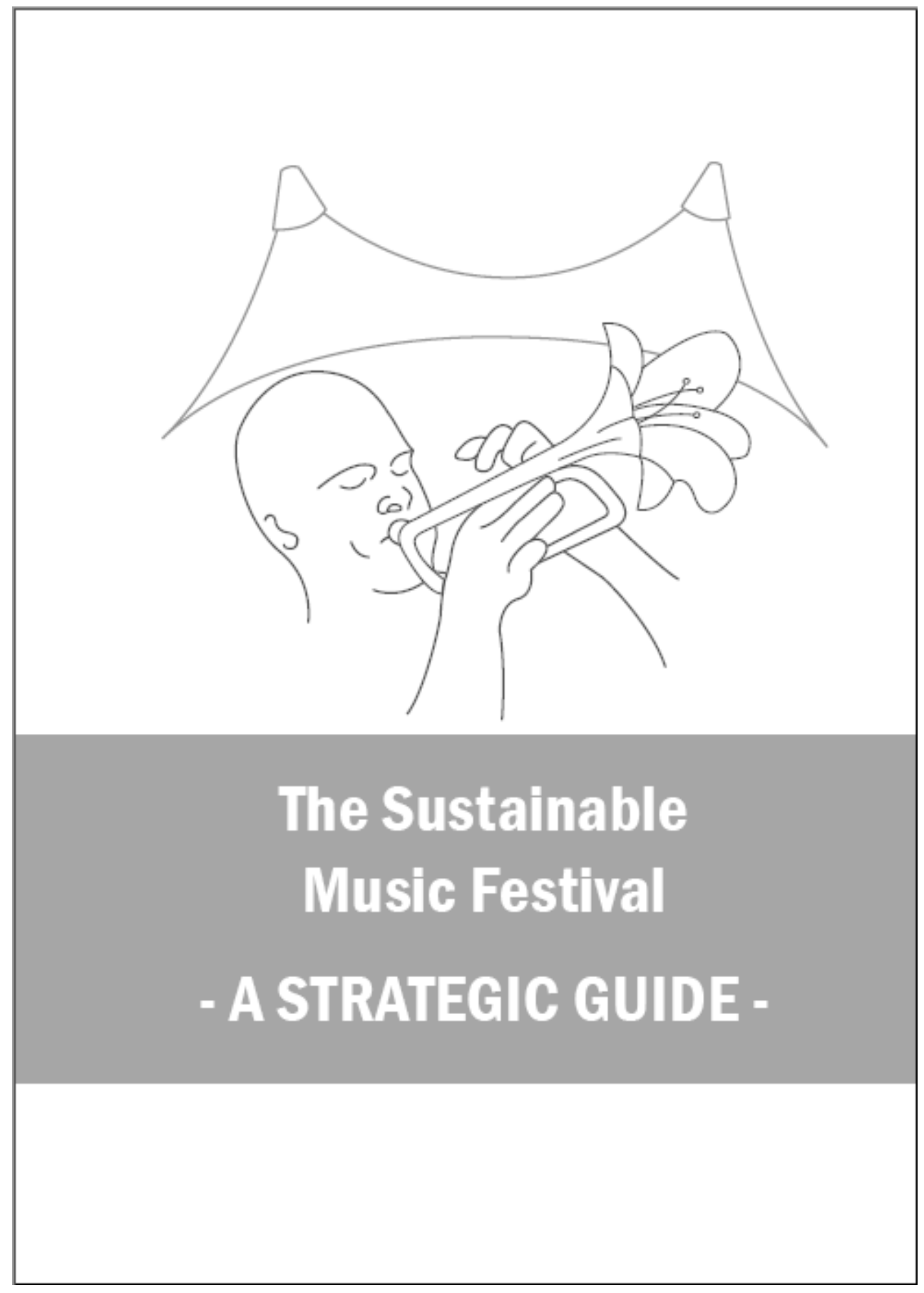

